\title{
Analytical determination of the vibration frequencies and buckling loads of slender reinforced concrete towers
}

\author{
Alexandre de M. Wahrhaftig ${ }^{a^{*}}$ \\ Marcelo A. da Silva ${ }^{b}$ \\ Reyolando M. L. R. F. Brasil ${ }^{b}$ \\ a Departamento de Construção e Estruturas, Escola Politécnica, Universidade Federal da Bahia (UFBA), Rua Aristides Novís, 02, 5o andar, \\ Federação, Salvador, BA, Brasil. E-mail: alixa@ufba.br \\ ${ }^{b}$ Centro de Engenharia, Modelagem e Ciências Sociais Aplicadas (CESC), Universidade Federal do ABC (UFABC), Rua Arcturus, 03 (Jd. \\ Antares), Edifício Delta, Sala 386, São Bernardo do Campo, SP, Brasil. E-mail: marcelo.araujo@ufabc.edu.br, reyolando.brasil@ufabc.edu.br \\ ${ }^{*}$ Corresponding author
}

http://dx.doi.org/10.1590/1679-78255374

\begin{abstract}
This study focused on improving the design of slender structures with reinforced concrete (RC) telecommunication towers as the main application. Analytical procedure based on Rayleigh's method to compute the first natural vibration frequency and the critical buckling load was development. All the nonlinearities present in the system were considered, in addition to the soil-structure interaction and the variation of the geometric properties along the length of the structure. The geometric nonlinearity and imperfections of the tower structure were computed as functions of the axial load using a geometric stiffness matrix. Further, the material nonlinearity was accounted for by reducing the flexural stiffness. As concrete structures exhibit viscoelasticity, creep was calculated using the Eurocode 2 model. The soilstructure interaction was modeled as a set of distributed springs. To validate the proposed method, the first frequency and critical buckling load were compared with those yielded by FEM simulations. The frequency results were in good agreement with those of the FEM simulations, indicating that the proposed method is sufficiently accurate for use in engineering design applications and easy to implement. On the other hand, the buckling load results obtained using the proposed method and FEM differed significantly, motivating further investigation.
\end{abstract}

\section{Keywords}

nonlinearity; creep; vibration; buckling; analytical procedure; finite element method.

\section{NOMENCLATURE}

\section{Properties}

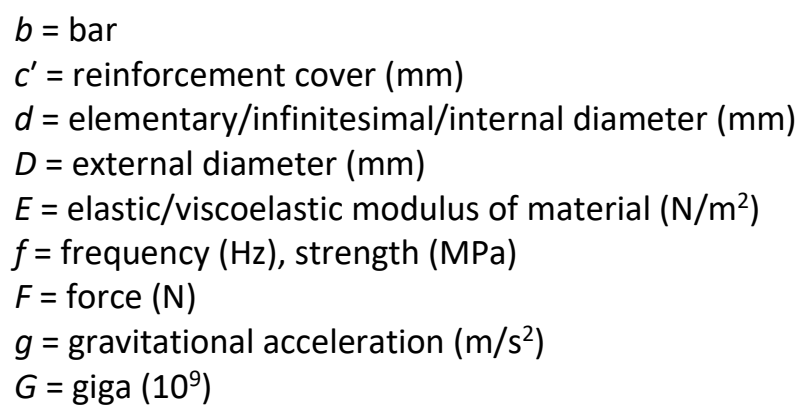




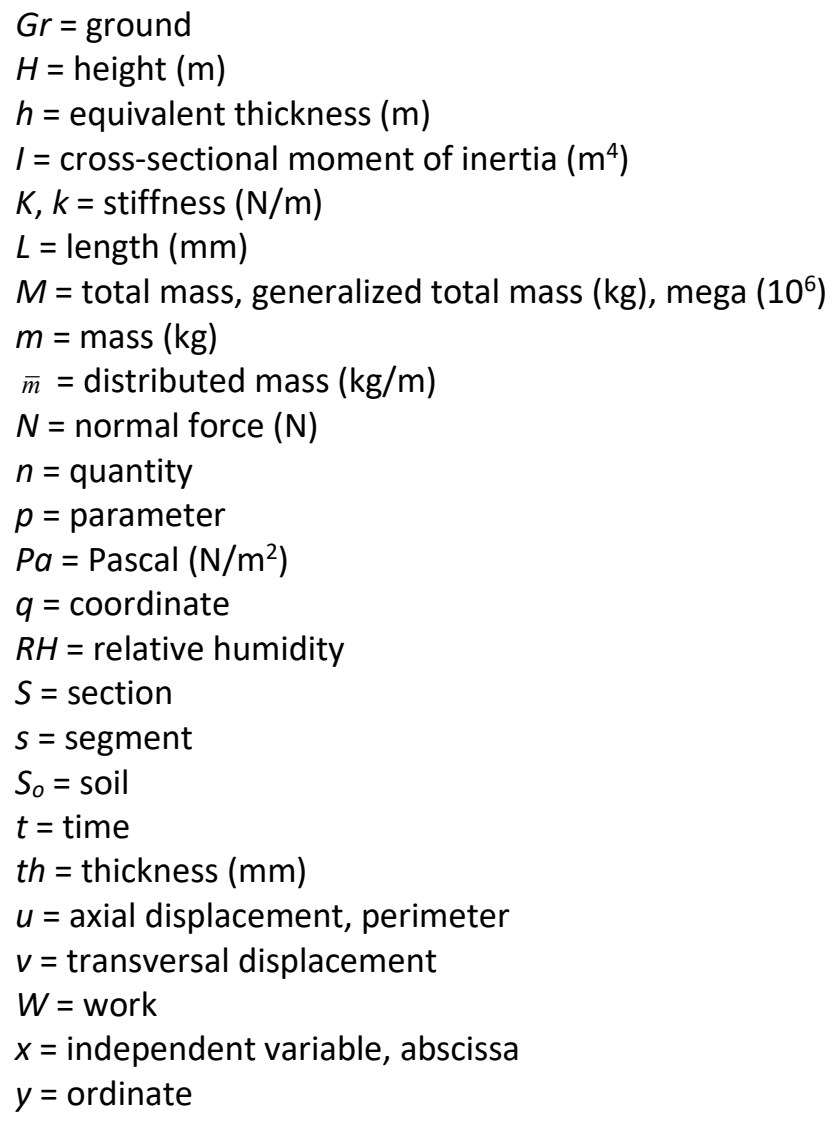

\section{Greek symbols}

$\Delta=$ variation, shift

$B=$ factor

$\Phi=$ eigenvector

$\delta=$ virtual work $(\mathrm{J})$

$\phi=$ function

$\eta=$ numeral

$\lambda=$ eigenvalues

$\pi=3.141592653589 .$.

$\rho=$ density $\left(\mathrm{kg} / \mathrm{m}^{3}\right)$

$\omega=$ frequency $(\mathrm{rad} / \mathrm{s})$

$\psi=$ eigenvalue

$\varphi=$ coefficient, factor

\section{Subscripts}

$c$ concrete

$E$, e relative to external, environment

$F L$ flexion

$g$ relative to geometric

$i$ series variable, initial

I relative to internal

$I N$ inertial

$m$ relative to foundation, mean

$s$ segment

$t$ relative to time

0 relative to elastic, lumped, geometric, time zero, equivalent

$1,2,3 \ldots$ first, second, third, etc. 


\section{Other notation}

spatial derivative

temporal derivative

\section{INTRODUCTION}

Telecommunication towers are slender beam-column structures that are frequently subjected to dynamic loading due to wind excitation. The wind speed is usually analyzed by considering two components: the mean wind speed and the floating wind speed (Eurocode Standard, 2010). The mean wind speed induces static loads, whereas the floating wind speed is responsible for the vibrations of such structures. According to Silva et al. (2013) and Silva and Brasil (2006), the dynamic response depends mainly on the first vibration frequency and the height of the structure. Hence, precise prediction of the first resonance frequency is necessary for dynamic analysis of such structures. As, for these cases, the frequencies are especially very low, suggesting proximity to the losing of stability, it is necessary, additionally, to verify the structural safe in relation to the vertical capacity of loading, understood it as the limit value for installation of antennas and platforms. Considering both aspects, the main objectives of this study were to develop a novel analytical expression for computing the first vibration frequency and modal shape of slender reinforced concrete $(\mathrm{RC})$ structures, to compute the critical buckling load considering geometrical and physical nonlinearities, and to compare the obtained values with those given by the finite element method (FEM), what is going to allow analysis of similar structural systems when exposed to the environmental wind.

In relation to the determination of the lateral forces produced by the wind, Vieira, Brito and Loredo-Souza (2018) point that it is an extreme complex problem because of the large number of variables involved. Amiri and Bucher (2017), affirmed that the design codes for wind loading provide useful instructions for engineers, but wind tunnel testing, which is generally employed for their evaluation, has several limitations. Consequently, field measurements can be very useful for verifying wind tunnel test data, allowing more realistic and reliable analysis. On the other hand, the comparison of numerical simulations and practical field results provides useful information for computing modal wind loads properly. Lateral forces due to wind produces lateral displacement on a structure. This configures an important aspect of the structural analysis for telecommunication systems. In terms of the serviceability state limit constraints to deflections at position of antennas are imposed in order to avoid discontinuity on communication service, transmission/reception of signal of cellular mobile phone. These deflections obviously depend on the lateral forces due to the wind, which in turn depend on the structural frequency (flexible or rigid body). Therein lies the importance of a correct calculation, which must consider all nonlinear aspects present in the problem. When calculating a slender concrete element must be observed that its frequency change on time because of the viscoelastic behavior of the material. Under wind action, if flexible, a structure vibrates around its balance position and presents displacement that can drive to the loss of signal. In this context, the permanent challenge for the mobile telecommunication operators is the establishment of a distribution system with a network configuration that be able to operate continuously to keep the transmission of the radio signal, ensuring local and long-distance coverage.

Taking into consideration the complexity characteristic of a phenomena of environmental nature, Durbey and Hansen (1996) presented several methods for computing the wind loads on structures. In addition, they stated that dynamic wind excitation can cause structures to resonate. Silva and Brasil (2006) and Simiu and Scanlan (1996) showed that for structures with low first frequencies, i.e., less than $1 \mathrm{~Hz}$, the dynamic effects of wind speed cannot be ignored, and the classical static analysis does not properly capture the structural behavior. They also noted that the fundamental frequency is the frequency that contributes the most to the dynamic behavior of the structure. This is general principle, which is applied either for a telecommunication tower as a building. Lo et al. (2017) who performed vibration tests of high-rise buildings mention that someone of factors have been investigated for many researchers in relation to wind action over these structures are their modal frequency and mode shapes. In this sense Pozos-Estrada and Hong (2015) point out that the value that most of the structures are sensitive to dynamic effect of the wind, especially tall buildings, falls within 0.05 to $0.5(\mathrm{~Hz})$. In that context is important to have clear that a telecommunication tower is a flexible and very slender structural element. Kwak and Kim (2004) affirmed that the failure of an RC column having a high slenderness ratio occurs well within the cross-section interaction diagram because of a pronounced second-order effect. In the case of columns with a slenderness ratio that does not exceed 100, failure occurs rather close to the material strength. The wind-induced collapse of three tall hyperbolic RC cooling towers in Ferrybridge, UK, in 1965, was investigated by Jia (2013), who concluded that buckling, in the classical sense of the term, was the most likely cause of the accident. 
The compressive capacity of a column can be quantified in several ways, one of which is based on the Euler buckling load (Uzny, 2011). The elastic buckling load of a pin-ended column was first determined by Euler in 1774 (ElSawy, Sweedan and Martini, 2009). However, he found it difficult to consider the effects of the self-weight of a column when determining its buckling response. Although this problem was finally solved by Greenhill in 1881 (Timoshenko and Gere, 1961), consideration of the column self-weight remains a subject of intense and extensive mathematical discussion (Lubbers et al., 2017), and several contributions have been made to the field since then. In the present study, the influence of the self-weight was considered when calculating the critical buckling load, which was computed by imposing a null value for the frequency. This dynamic approach was previously adopted by Deng et al. (2017) to calculate the stability of a multi-span beam used to represent a fluid-conveying pipe. In the present study, three components were considered to describe the elastic behavior of the structural system: the structure material and its nonlinear behavior, the geometric nonlinearity, and the soil.

In relation to the material nonlinearity of the concrete Liu et al. (2016) developed a mathematical model to investigate the influence of cracks on the dynamic behavior of a cantilever beam. For this purpose, they developed a model with local flexibility at the crack tips to analyze the beam vibrations. Challamel et al. (2005) performed several numerical simulations to study the effects of creep and the strain rate on the failure stresses of quasi-brittle materials. In the present study, the effects of the material nonlinearities were captured by reducing the flexural stiffness, while the creep effects were computed in accordance with the relevant Eurocode 2 model (2004).

The geometric nonlinearity whether produced by the eccentricity of the load applied to a column or a constructive imperfection can be considered as reducing the stiffness of the structure in terms of its geometric stiffness, as recommended by Wilson and Habibullah (1987), because it is a function of existent axial forces. The effect of the axial load on the fundamental vibration frequency was further examined by Wahrhaftig and Brasil (2016), who studied a cantilever beam with large initial displacement. The geometric stiffness is independent of the elastic properties of the material, as explained by Noh (2006). Houmat (2015) applied the concept of geometric stiffness to the free vibration of laminates with variable stiffness along the structure domain. Further, Challamel and Hellesland (2013) performed buckling and post-buckling analysis of softening columns composed of quasi-brittle materials, specifically, RC columns, by applying eccentric vertical loads. They used continuum damage mechanics to include the influence of micro cracking on the material. Zuo, Bi, and Hao (2018) noted that the soil-structure interaction could not be ignored, because, particularly in the case of a monopile foundation, there is an important interaction with and a significant influence on the dynamic behavior of the structure. Amini et al. (2018) investigated this phenomenon associated with the soilstructure interaction. They asserted that a major challenge when modeling structures under wind loading is proper design of the foundations.

Owing to the large number of factors that influence the structures analyzed in this study, whose behavior is governed by partial non-linear differential equations, the exact response cannot be computed analytically, affirm Awrejcewicz et al. (2014). Challamel et al. (2015a) noted that, in numerical approaches, unsolvable mathematical equations of continuous systems are often converted into finite numbers of variables associated with discrete equivalent systems to reduce the complexity of the problem. According to Challamel et al. (2015b), the possibility of solving complex continuous systems using a computer makes the discretization approach particularly advantageous over continuous methods. Alternatively, a continuous system can be reduced to a single-degree-of-freedom (SDOF) system. In this approach, the system is restricted to have only one shape mode, and the system properties can be expressed as functions of a single generalized coordinate. This technique was proposed by Lord Rayleigh (1877) in his work on elastic system vibrations. Most actual structures are complex systems with properties that vary along their lengths. In such cases, the integrals obtained using Rayleigh's method must be solved within the limits established for each interval, i.e., generalized properties can be obtained for each discrete segment of the structure. Whereas Rayleigh's method involves only scalar numbers, in the FEM, it is necessary to deal with matrices with the order given by the number of degrees of freedom considered in the mathematical model.

\section{CREEP CONSIDERATION}

\subsection{Overview}

Creep is the gradual increase of structural deformation with time, and it is a typical occurrence in concrete structures owing to the viscoelastic nature of concrete. It is important to consider creep in the ultimate limiting state when verifying the stability of a slender member under compression, because the stiffness of such a member varies with the rheology of the material. Charpin and Sanahuja (2017) noted that understanding concrete behavior under extended sustained loading had emerged as an important topic since the study performed by Granger (1995), who 
highlighted the importance of conducting multiaxial tests to model the biaxial creep that occurs in concretecontainment buildings in nuclear power plants accurately. In 2004, this requirement prompted the initiation of a broad experimental program in France to investigate multiaxial creep in structures. A viscoelastic correlation model was obtained to consider the creep behavior of concrete. Granger (1995) further observed that when stress remains constant over time, deformation can be calculated classically by replacing the Young's modulus with a deferred or temporal modulus of elasticity. Boshoff and van Zijl (2007) also used a temporal modulus and proposed an expression for the long-term material stiffness by simply adjusting the Young's modulus using a creep coefficient. Hamed and Bradford (2010) performed a similar analysis in their mathematical investigation of creep in RC beams strengthened with fiber-reinforced polymers. Han et al. (2017a) experimentally investigated creep in a concrete-filled steel tube. In addition, Irfan-ul-Hassan et al. (2016) established the relationship between the modulus of elasticity and time and quantified the Young's modulus by performing an experimental examination of cylindrical specimens.

To confirm the occurrence of creep in concrete structures subjected to tensile and compressive loads, Rossi, Tailhan, and Le Maou (2013) conducted an experimental study that revealed the apparent equivalence of compressive and tensile creep under curing conditions. Ranaivomanana, Multon, and Turatsinze (2013) also performed an experimental investigation using different levels of stress, and they concluded that nonlinear stress behavior occurs under compression that exceeds $30 \%-50 \%$ of the concrete compressive strength. In the present study, the compressive stress was varied from $0.14 \%$ of the compressive strength at the tower tip to $3.62 \%$ of that at the base. Assmann and Reinhardt (2014) used concrete specimens that included polymers to experimentally investigate creep under tension. Further, Charpin and Sanahuja (2017) calculated the Poisson's ratio of concrete using classical integral expressions of the linear viscoelastic behavior of concrete, thereby assuming isotropic linear viscoelastic creep behavior in a concrete structure.

Mathematically, creep can be characterized by an increase in the initial elastic deformation through viscous deformation, resulting in deformation as a function of time. Consequently, the modulus of elasticity must also be represented as a temporal function. Theoretically, creep strain can be calculated under arbitrary load conditions by using the superposition principle. However, it is difficult to distinguish between the effects of creep and those of elastic strain during initial loading, as reported by Su et al. (2017). This difficulty arises from the fact that it is not possible to distinguish between the beginning of immediate deformation and long-term deformation, as immediate deformation already includes a certain portion of the creep deformation. Qian and Kawashima (2016) investigated the behavior of concrete specimens and observed that the viscosity increased when the applied stress was relatively low, causing the material to yield and viscoelastic solid-like behavior to appear. Rheological models for evaluating creep were developed by Sellier et al. (2016), who performed a series of computational simulations in an FEM environment. A viscoelasticplastic model that superposes the strains obtained using the Maxwell, Kelvin, Bingham, and Saint-Venant models was proposed by Han et al. (2017b) to describe early-age creep in concrete. This model essentially represents a modified version of a system that maintains the conventional initial viscoelastic behavior of concrete. In the field of structural analysis, Pascon (2018) employed the well-known three-parameter model, normally used to represent the behavior of a solid, to numerically evaluate the time-dependent mechanical behavior and large deformation of functionally graded visco-hyperelastic materials. A similar strategy of using a set of a spring and a damper for representing the rheological behavior of a material was adopted by Milašinovic' and Landovic (2018) for studying viscoelastoplastic vibrations in the analysis of low cycle fatigue in internally damped inelastic frame structures. A more complex rheological model was recently developed and experimentally validated by Delsaute, Torrenti, and Staquet (2017).

Awruch and Gomes (2015) suggested that the enduring effects of loading a structure originate from the timedependent deformations that occur during the first few months of loading but last for most of the service life of the structure. This characteristic sometimes results in displacement of the same order as that of the instantaneous deformation induced by a service load. Mehta, Monteiro and Filho (1994) noted that the slow deformation of a material depends on parameters such as the loading direction, speed, and duration; material moisture content; ambient temperature; and relative humidity. The rheological properties of concrete that are essential to understanding creep behavior were recently discussed in detail by Jiao et al. (2017).

The effects of creep on the dynamic behavior of structures have been investigated by several researchers. On the basis of CEB-FIP 1990 (Comité Européen du Béton (CEB)-Fédération Internationale du Béton (FIB) or International Federation for Structural Concrete), which includes the recommendations of the European Standard (2004) (EN 1992-11 - Eurocode 2: Design of concrete structures - Part 1: General rules and rules for buildings) Yang, Chen, Zhang, and Fan (2016) investigated the creep induced by the response of a prestressed concrete railway bridge using a temporal function and found that the phenomenon and its associated deformation rate are influenced by temperature. Temperature is particularly crucial for the operation of high-speed trains because irregularities caused by temperature- 
induced creep and deformation of the railway concrete affect the wheel unloading rate and vertical acceleration of the train, affirms Wang (2014). Suspension bridges constitute a different type of slender structure, and their creep behavior accounts for a significant portion of the required structural analysis. Arco et al. (2001) observed that the creep response of a suspension bridge and its analysis were complicated by the combined effects of the geometric nonlinearity, pretension, and time-variant material behavior.

\subsection{Creep as addressed in Eurocode 2}

As noted by Hołowaty (2015), the creep model in the European Standard EN 1992-1-1 (Eurocode 2, 2004) is based on the CEB-FIP Model Code (1990). In addition, the method specified in Eurocode 2 for incorporating creep into structural analysis considers the effects of the creep behavior and its variation with time. Eurocode 2 provides hypothetical and model limitations for creep calculation, wherein the creep coefficient $\varphi$ is predicted as a function of the tangent modulus of elasticity $E_{c}$, which can be considered as the secant modulus of elasticity $E_{c m}+5 \%$. The creep deformation of concrete is computed by multiplying the immediate deformation by the creep coefficient. The total concrete deformation at time $t$, under constant temperature, can be obtained as the sum of the terms that represent the immediate deformation, creep, and shrinkage, as defined by Neville (1997). The method specified in EN 1992-1-1 (2004) makes no distinction between slow deformation and fast-reversible, slow-irreversible, or slow-reversible deformation. All the factors of the concrete, load, and environment are calculated under the assumption that they remain constant over the considered time interval, affording a specific result for the creep coefficient $\varphi$. This coefficient is then directly introduced into the slow deformation equation and used as input data for various procedures. The basic equations for determining the creep coefficient of concrete over time are based on the average compressive strength $f_{c m}\left(f_{c m}=f_{c k}+8, f_{c k}\right.$ in $\left.\mathrm{MPa}\right)$. The creep coefficient $\varphi\left(t, t_{0}\right)$, as defined in Eq. (1), is the product of two macrofactors, namely $\varphi_{0}$ and $B_{c}\left(t, t_{0}\right)$, which respectively characterize the effects of the rheological properties of the concrete under environmental conditions and the evolution of creep with time after loading of the structure.

$\varphi\left(t, t_{0}\right)=\varphi_{0} \beta_{c}\left(t, t_{0}\right)$

The first macrofactor $\varphi_{0}$ defined in Eq. (2) consists of three microfactors. The first microfactor $\varphi_{R H}$ (given by Eq. (3) for average concrete compressive strengths $\leq 35 \mathrm{MPa}$ and by Eq.(4) for greater than $35 \mathrm{MPa}$ ) accounts for the effects of the environmental relative humidity $R H$, equivalent thickness $h_{0}$ of the member (a function of the cross-sectional area $\left.A_{c}\right)$, and external perimeter $u_{e}$ of the member in contact with the environment. The second microfactor $B\left(f_{c m}\right)$ (Eq. (6)) represents the direct effect of the resistance on $\varphi_{0}$. The third microfactor $B\left(t_{0}\right)$ (Eq. (7)) represents the age of the concrete at the beginning of loading, i.e., at $t_{0}$.

$\varphi_{0}=\varphi_{R H} \beta\left(f_{c m}\right) \beta\left(t_{0}\right)$

$\varphi_{R H}=1+\frac{1-R H / 100}{0.1 \sqrt[3]{h_{0}}}$, for $f_{c m} \leq 35 \mathrm{MPa}$

$\varphi_{R H}=\left[1+\frac{1-R H / 100}{0.1 \sqrt[3]{h_{0}}} \alpha_{1}\right] \alpha_{2}, f_{c m}>35 M P a$

$h_{0}=\frac{2 A_{c}}{u_{e}}(5)$

$\beta\left(f_{c m}\right)=\frac{16.8}{\sqrt{f_{c m}}}$

$\beta\left(t_{0}\right)=\frac{1}{\left(0.1+t_{0}^{0.20}\right)}$

The second macrofactor $B_{c}\left(t, t_{0}\right)$ (Eq. (8)) is a function of the coefficient $B_{H}$ (given by Eq. (9) for average concrete compressive strengths $\leq 35 \mathrm{MPa}$ and by Eq.(10) for upper), and it is used to regulate the combined effects of the 
relative humidity and the equivalent member thickness. The percolation path of the adsorbed water in a robust section of concrete is so large that the effects of creep due to differential moisture are less important for slimmer sections.

$$
\begin{aligned}
& \beta_{c}\left(t, t_{0}\right)=\left[\frac{\left(t-t_{0}\right)}{\beta_{H}+\left(t-t_{0}\right)}\right]^{0.3} \\
& \left.\beta_{H}=1.5[1+(0.012 R H))^{18}\right] h_{0}+250 \leq 1500, \text { for } f_{c m} \leq 35 \mathrm{MPa} \\
& \left.\beta_{H}=1.5[1+(0.012 R H))^{18}\right] h_{0}+250 \alpha_{3} \leq 1500, f_{c m}>35 \mathrm{MPa} \\
& \alpha_{1}=\left(\frac{35}{f_{c m}}\right)^{0.7}, \alpha_{2}=\left(\frac{35}{f_{c m}}\right)^{0.2}, \alpha_{3}=\left(\frac{35}{f_{c m}}\right)^{0.5}
\end{aligned}
$$

Thus, the creep coefficient can be obtained using Eq. (1), and the temporal function that describes the deformation in accordance with EN 1992-1-1 can be expressed as

$$
\varepsilon\left(t, t_{0}\right)=\sigma_{c}\left(t_{0}\right)\left[\frac{1}{E_{c}\left(t_{0}\right)}+\frac{\varphi\left(t, t_{0}\right)}{E_{c}\left(t_{28}\right)}\right]
$$

Based on the above equations, the modulus of elasticity with respect to time can be expressed as

$$
E\left(t, t_{0}\right)=\frac{1}{\frac{1}{E_{c}\left(t_{0}\right)}+\frac{\varphi\left(t, t_{0}\right)}{E_{c}\left(t_{28}\right)}},
$$

where $E_{c}\left(t_{0}\right)$ is the modulus of elasticity at the beginning of loading and $E_{c}\left(t_{28}\right)$ is the modulus of elasticity 28 days after the commencement of loading.

\section{CASE STUDY STRUCTURE}

\subsection{Description of the practical problem}

The practical problem considered in the present study involved the calculation of the first natural vibration frequency and the critical buckling load of an actual slender RC tower (or pole), with its inherent geometrical and material nonlinearities (see Figure 1). Such RC towers are commonly used to support antenna systems for cellular telephony services. The geometrical details of the considered tower are shown in Figure 1(b). The geometric division of the structure and the cross-sections along the tower are shown in Figure 2, where $s$ denotes the segment, $S$ denotes the section type, $g$ is the gravitational acceleration, $G r$ denotes the ground, $d_{b}$ is the reinforcement bar diameter, $n_{b}$ is the number of reinforcement bars, and $c^{\prime}$ is the reinforcement covering. 

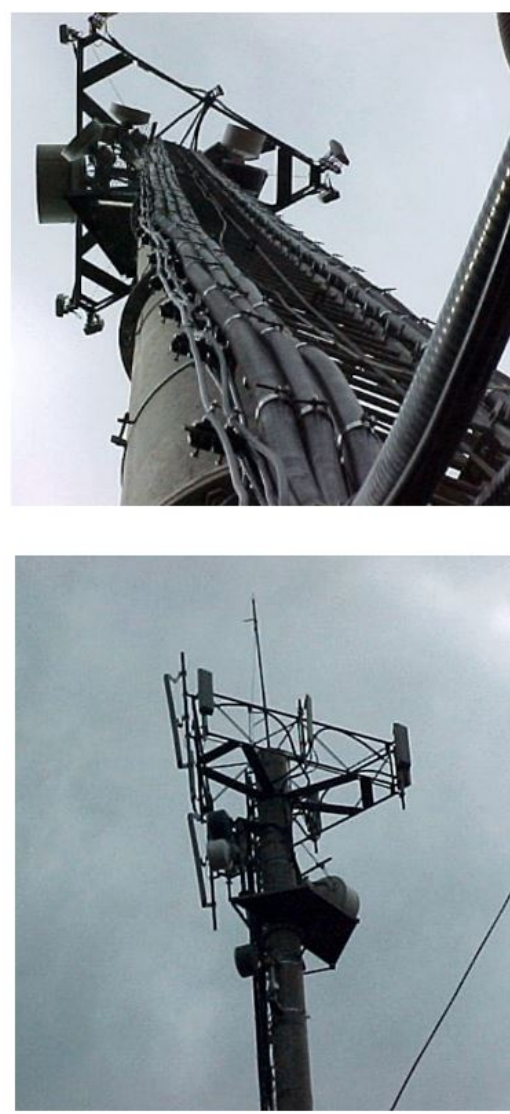

(a) Photographs of the tower

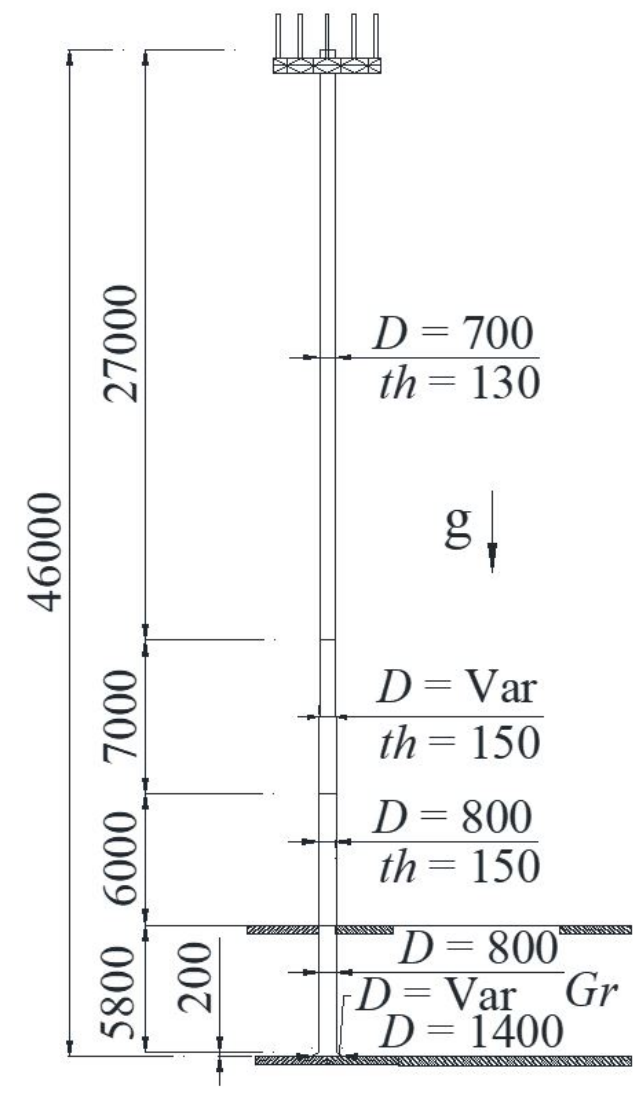

(b) Geometrical details of the tower (in millimeters). Var = variable, $G r=$ ground

Figure 1. Case study of mobile communication tower.

The tower has a height of $46 \mathrm{~m}$ and a hollow circular cross-section. The external diameter and wall thickness of each structural segment of the tower are denoted as $D$ and th $(\mathrm{mm})$, respectively. Figure 2 shows the cross-section along the length of the tower. The slenderness ratio of the tower is 334 . A set of antennae and a platform are installed at the top of the structure, contributing $1097.76 \mathrm{~kg}$ to the total mass of the structure. Cables and a ladder are installed along the length of the structure, yielding a distributed mass of $40 \mathrm{~kg} / \mathrm{m}$. The centrifuged RC pole and foundation shaft have densities of $2600 \mathrm{~kg} / \mathrm{m}^{3}$ and $2500 \mathrm{~kg} / \mathrm{m}^{3}$, respectively. The foundation of the tower is composed of a relatively deep shaft with a bell diameter and length of $1400 \mathrm{~mm}$ and $200 \mathrm{~mm}$, respectively, and a shaft diameter and length of $800 \mathrm{~mm}$ and $5800 \mathrm{~mm}$, respectively. In this study, the lateral soil resistance was represented by an elasticity parameter with a magnitude of $2668.93 \mathrm{kN} / \mathrm{m}^{3}$, corresponding to the total lateral stiffness. The concrete resistance was considered to be $45 \mathrm{MPa}$ and $20 \mathrm{MPa}$ in the pole and foundation, respectively. The physical nonlinearity of the RC was computed in accordance with the recommendations of the NBR 6118:2014 (2014) - Design of concrete structures Procedure, from the Brazilian Association for Standardization (ABNT), suggesting a 50\% reduction of the gross moment of inertia. Note that Brasil et al. (2007) and Silva et al. (2013) investigated the same problem under similar conditions and confirmed that the effective flexural stiffness was no less than $40 \%$ of the total stiffness when the structure was subjected to the designed gross moment of inertia. The details of the tower and installed equipment are summarized in Table 1.

Table 1. Physical details of the tower structure and installed equipment.

\begin{tabular}{lcc}
\hline \hline \multicolumn{1}{c}{ Object } & Height & Density/unitary mass/lumped mass \\
\hline Tower & $6-46 \mathrm{~m}$ & $2600 \mathrm{~kg} / \mathrm{m}^{3}$ \\
Foundation & $0-6 \mathrm{~m}$ & $2500 \mathrm{~kg} / \mathrm{m}^{3}$ \\
Ladder + cables & $6-46 \mathrm{~m}$ & $40 \mathrm{~kg} / \mathrm{m}$ \\
Antennae and platform & $46 \mathrm{~m}$ & $1097.76 \mathrm{~kg}$ \\
\hline \hline
\end{tabular}




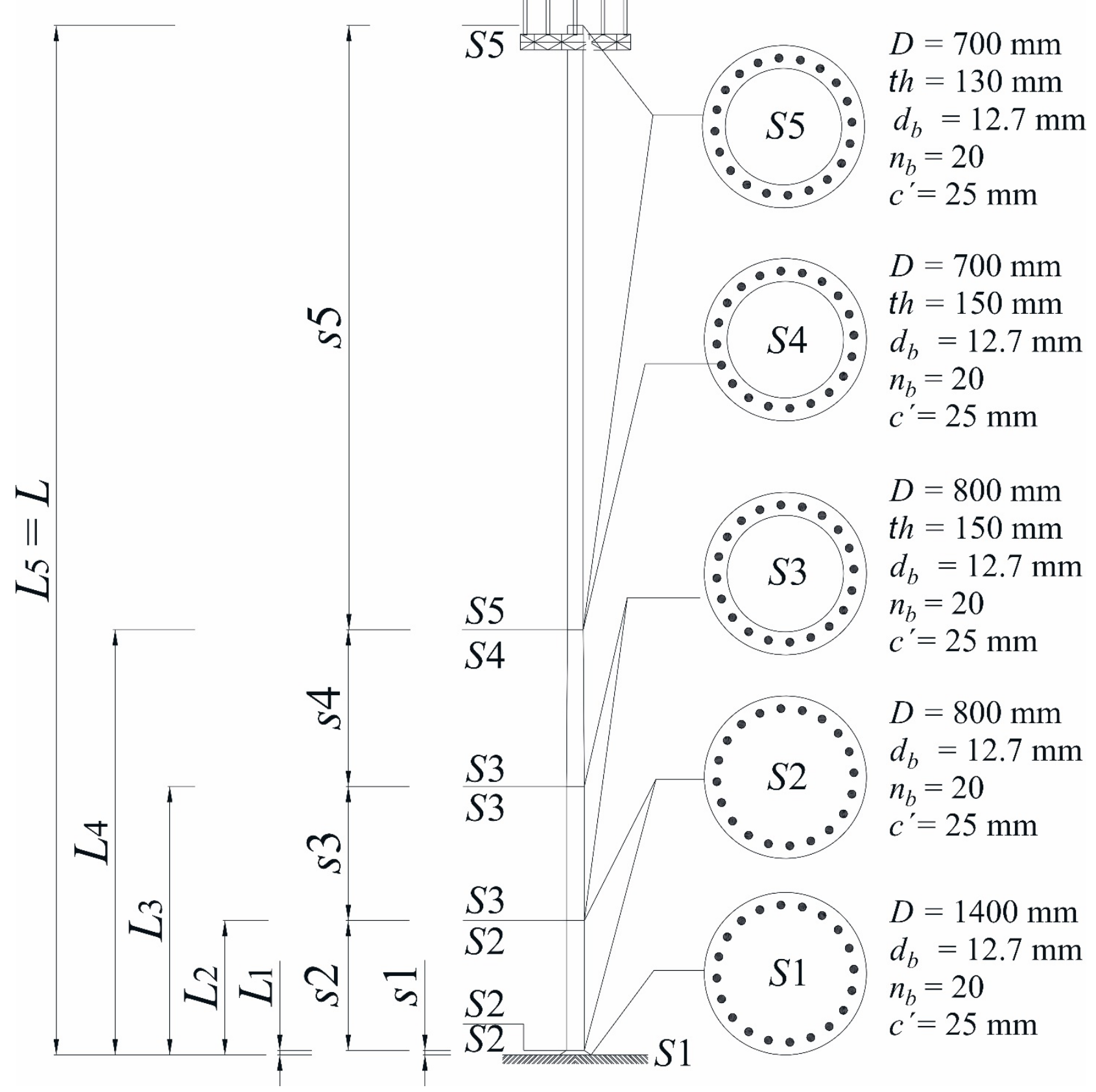

Figure 2. Segments and cross-sections along the tower.

As the focus of the present study was the RC structure, it was necessary to account for the contribution of the reinforcement bars to the moment of inertia of the entire cross-section, which was accomplished by homogenization. A circular-ring cross-section was assumed, with external diameter $D$, wall thickness th (for the pole, the foundation does not have a thickness th because it is a full cross-section), and reinforcement covering $c^{\prime}(=25 \mathrm{~mm})$. The modulus of elasticity of the steel reinforcement $\left(E_{s t}\right)$ is $205 \mathrm{GPa}$. The number of bars $\left(n_{b}\right)$ distributed along the periphery of the cross-section is 20, and each bar has a diameter $\left(d_{b}\right)$ of $12.7 \mathrm{~mm}$, as stated in Figure 3(a). Each reinforcement bar $b_{i}$ assumes a given position $i$ in the cross-section domain, defined by $R_{b i}$ and $\vartheta_{i}$, as shown in Figure 3(b). 


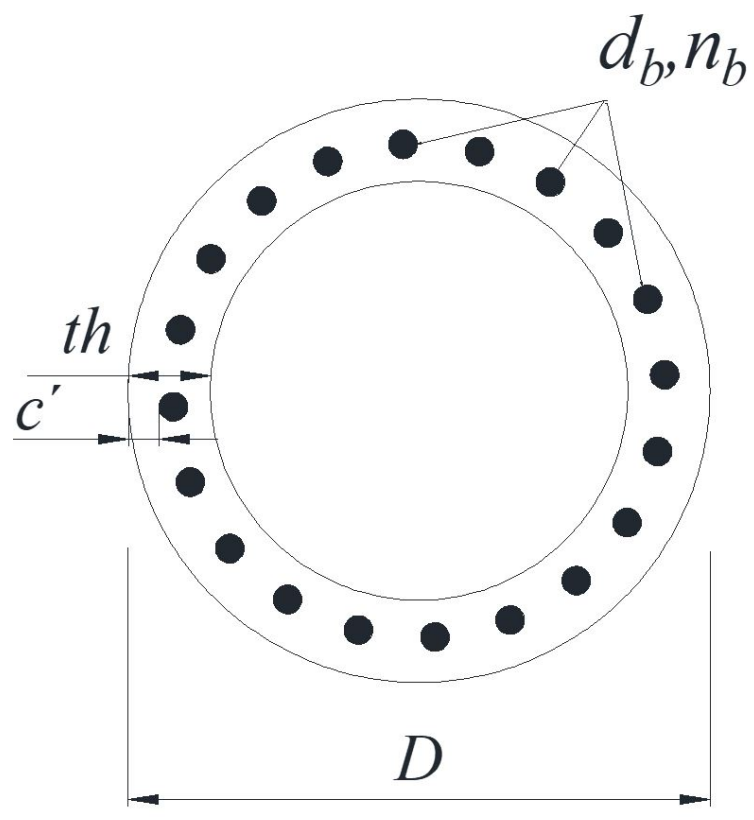

(a) Arrangement of the reinforcing bars

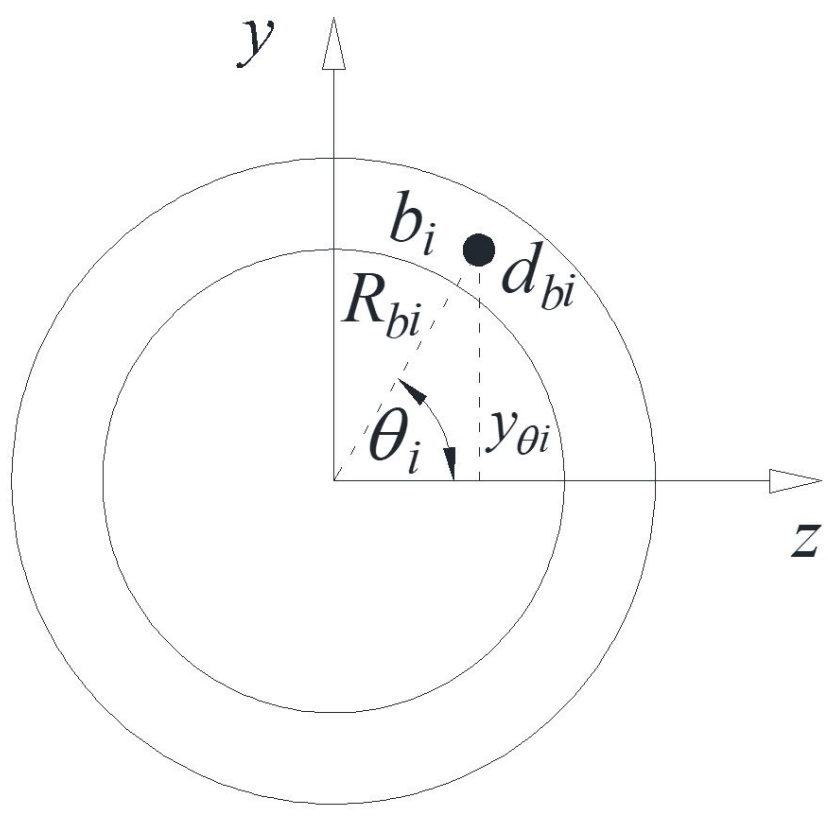

(b) Position of the ith bar

Figure 3. Cross-section adopted for the RC structure

The variable $R_{b i}$ describes the position of the barycenter of each bar $b_{i}$ relative to the barycenter of the crosssection. Because all the bars have the same radius $R_{b i}$, the following expression applies:

$R_{b i}=\frac{D}{2}-c^{\prime}-\frac{d_{b i}}{2}$,

where $c^{\prime}$ is the covering and $d_{b i}$ is the diameter of the ith bar. Because $\vartheta_{i}$ is an independent variable that takes values between 0 and $2 \pi$, the distance between the center of each bar and the axis of the cross-section can be expressed as

$y\left(\theta_{i}\right)=\sin \left(\theta_{i}\right) R_{b i}$.

The spacing $s p$ between the centers of adjacent bars is given by

$s p=\frac{2 \pi R_{b i}}{n_{b}}$,

where $n_{b}$ denotes the number of longitudinal bars. The angular phase shift $\Delta \vartheta$ between two adjacent bars is thus

$\Delta \theta=\frac{s p}{R_{b i}}$.

The moment of inertia of each bar about the cross-section barycenter, $l_{\text {si }}$, can be computed using the following expression:

$I_{s i}\left(\theta_{i}\right)=\frac{\pi d_{b i}^{4}}{64}+y\left(\theta_{i}\right)^{2} \frac{\pi d_{b i}^{2}}{4}$

The homogenized moment of inertia of the reinforcement steel, $I_{h s}$, can be expressed as

$I_{h s}=\sum_{\theta_{i}} I_{s i}\left(\theta_{i}\right)\left(\frac{E_{s t}}{E_{c i}}-1\right)$ 
The moment of inertia of the concrete in the cross-section (without neglecting the steel domain) for the pole and foundation are, respectively, given by

$$
I_{c o n}=\frac{\pi}{64}\left[D^{4}-(D-2 t h)^{4}\right] \text {, and } I_{c o n}=\frac{\pi D^{4}}{64},
$$

while the total homogenized moment of inertia of the cross-section is given by $I_{\text {tot }}=I_{\text {con }}+I_{\text {hs }}$. Therefore, the factor $F_{h s \text {, }}$ which is used to multiply the nominal moment of inertia $I_{h s}$, computed using the total moment of inertia of the reinforcement steel, can be written as

$$
F_{h s}=1+\frac{I_{h s}}{I_{c o n}} .
$$

Therefore, the values of the factor $F_{h s}$, which multiplies the nominal moment of inertia for each section from 1 to 5 , were $F_{h 1}=1.0199, F_{h 2}=1.0568, F_{h 3}=1.0811, F_{h 4}=1.0671$, and $F_{h 5}=1.0859$, respectively.

\subsection{Parameters of the practical problem}

The parameters employed in the analytical and computational process conducted during this study are summarized in Table 2. The modulus of elasticity of the concrete was based on Eurocode 2.

Table 2. Parameters used for the analysis and computations.

\begin{tabular}{cc}
\hline \hline Parameter & Value \\
\hline Compressive strength of tower concrete & $f_{c m}=45 \mathrm{MPa}$ \\
Elastic modulus of tower concrete at 28 days & $E_{c}=38097.35 \mathrm{MPa}$ \\
Reduced elastic modulus of tower concrete & $0.5 E_{c}=19048.67 \mathrm{MPa}$ \\
Compressive strength of foundation concrete & $f_{c m}=20 \mathrm{MPa}$ \\
Elastic modulus of foundation concrete at 28 days & $E_{f}=31460.05 \mathrm{MPa}$ \\
Reduced elastic modulus of foundation concrete & $0.5 E_{f}=15730.02 \mathrm{MPa}$ \\
Density of structure concrete & $\rho=2600 \mathrm{~kg} / \mathrm{m}^{3}$ \\
Density of foundation concrete & $\rho_{1}=2500 \mathrm{~kg} / \mathrm{m}^{3}$ \\
Lumped mass at tower top & $m_{0}=1097.76 \mathrm{~kg}$ \\
Additional distributed mass per unit height & $\bar{m}_{e}=40 \mathrm{~kg} / \mathrm{m}$ \\
Elastic parameter of soil & $S_{o p}=2668.93 \mathrm{kN} / \mathrm{m}^{3}$ \\
Gravitational acceleration & $g=9.806650 \mathrm{~m} / \mathrm{s}^{2}$ \\
\hline \hline
\end{tabular}

In Figure 2, the height of each segment $s$ of the structure is defined from the bottom to the top in the following sequence: $s 1$ extends from 0 to $L_{1}, s 2$ extends from $L_{1}$ to $L_{2}, s 3$ extends from $L_{2}$ to $L_{3}$, s4 extends from $L_{3}$ to $L_{4}$, and $s 5$ extends from $L_{4}$ to $L_{5}(=L)$. Points $L_{1}, L_{2}, L_{3}, L_{4}$, and $L_{5}$ are at elevations of $0.2,6.0,12.0,19.0$, and $46.0 \mathrm{~m}$, respectively. For the base of the foundation, $D_{1}=1400 \mathrm{~mm}, A_{l}=\frac{\pi}{4} D_{l}{ }^{2}$, and $I_{l}=\frac{\pi}{64} D_{l}^{4} F_{h l}$. For the shaft, $D_{2}=800 \mathrm{~mm}, A_{2}=\frac{\pi}{4} D_{2}{ }^{2}$, and $I_{2}=\frac{\pi}{64} D_{2}^{4} F_{h 2}$. The variation of the segment diameter between the base and the shaft is represented by the linear relationship $D_{1}(x)=\frac{D_{2}-D_{1}}{L_{1}} x+D_{1}$. Thus, the area and moment of inertia of each segment are given by $A_{I}(x)=\frac{A_{2}-A_{1}}{L_{1}} x+A_{1}$ and $I_{1}(x)=\frac{I_{2}-I_{1}}{L_{1}} x+I_{1}$, respectively. The external diameter and thickness of the initial segment of the superstructure, $D_{3}$ and $t_{3}$, are $800 \mathrm{~mm}$ and $150 \mathrm{~mm}$, respectively. Hence, the internal diameter, area, and moment of inertia of the segment are given by $d_{3}=D_{3}-2 t h_{3}, A_{3}=\frac{\pi}{4}\left(D_{3}{ }^{2}-d_{3}{ }^{2}\right)$, and $I_{3}=\frac{\pi}{64}\left(D_{3}{ }^{4}-d_{3}{ }^{4}\right) F_{h 3}$, respectively. Similarly, $D_{5}, t h_{5}, d_{5}, A_{5}$, and $I_{5}$, which denote the external diameter, thickness, internal diameter, area, and moment of inertia of the last segment, respectively, are $D_{5}=700 \mathrm{~mm}, t h_{5}=130 \mathrm{~mm}, d_{5}=D_{5}-2 t h_{5}, A_{5}=\frac{\pi}{4}\left(D_{5}{ }^{2}-d_{5}{ }^{2}\right)$, and $I_{5}=\frac{\pi}{64}\left(D_{5}{ }^{4}-d_{5}{ }^{4}\right) F_{h 5}$. These two segments are connected by the segment $s 4$ of variable cross-section. This begins with a diameter and thickness equal 
to those of the third section and ends with those of the fifth section (i.e., $t_{4}=150 \mathrm{~mm}$ ). Its area and moment of inertia can be expressed as $A_{4}=\frac{\pi}{4} D_{4}{ }^{2}$ and $I_{4}=\frac{\pi}{64}\left(D_{4}{ }^{4}-d_{4}{ }^{4}\right) F_{h 4}$, respectively. Therefore, the internal diameter, area, and moment of inertia of the variable section are given by $D_{4}(x)=\frac{D_{4}-D_{3}}{L_{4}-L_{3}}\left(x-L_{3}\right)+D_{3}, \quad A_{4}(x)=\frac{A_{4}-A_{3}}{L_{4}-L_{3}}\left(x-L_{3}\right)+A_{3}$, and $I_{4}(x)=\frac{I_{4}-I_{3}}{L_{4}-L_{3}}\left(x-L_{3}\right)+I_{3}$, respectively.

\section{ANALYTICAL PROCEDURE}

\subsection{Overview of the mathematical development of the SDOF model}

As observed by Clough and Penzien (1993), the approximation of an infinite-degree-of-freedom system, such as the slim RC tower considered in the present study, requires the use of an SDOF system to formulate the equations of motion for the continuous problem. This SDOF system (a basic cantilever frame element with undamped free movement, as shown in Figure 4) was assumed to consist of a bar possessing either constant or variable properties, such as geometry, elasticity (or even viscoelasticity), and density, represented by $I_{s}(x), E_{s}(t)$, and $\bar{m}_{s}(x)$, respectively, along its length, defined between ordinates $L_{s}$ and $L_{s-1}$, as shown in Figure 2 . A set of springs of variable stiffness $k_{s o s}(x)$ was laterally attached to the system to model the soil-structure interactions. In addition to its self-weight and distributed mass, the system supported a mass $m_{0}$ at its tip. $N_{s}(x)$ denotes the variable normal generalized force, while $u(t)$ and $q(t)$ denote the vertical and lateral displacements, respectively, of the tip section. The essential properties of the system are its flexural stiffness and mass per unit length. It was further assumed that the motion of the system did not alter the direction of the normal force. 


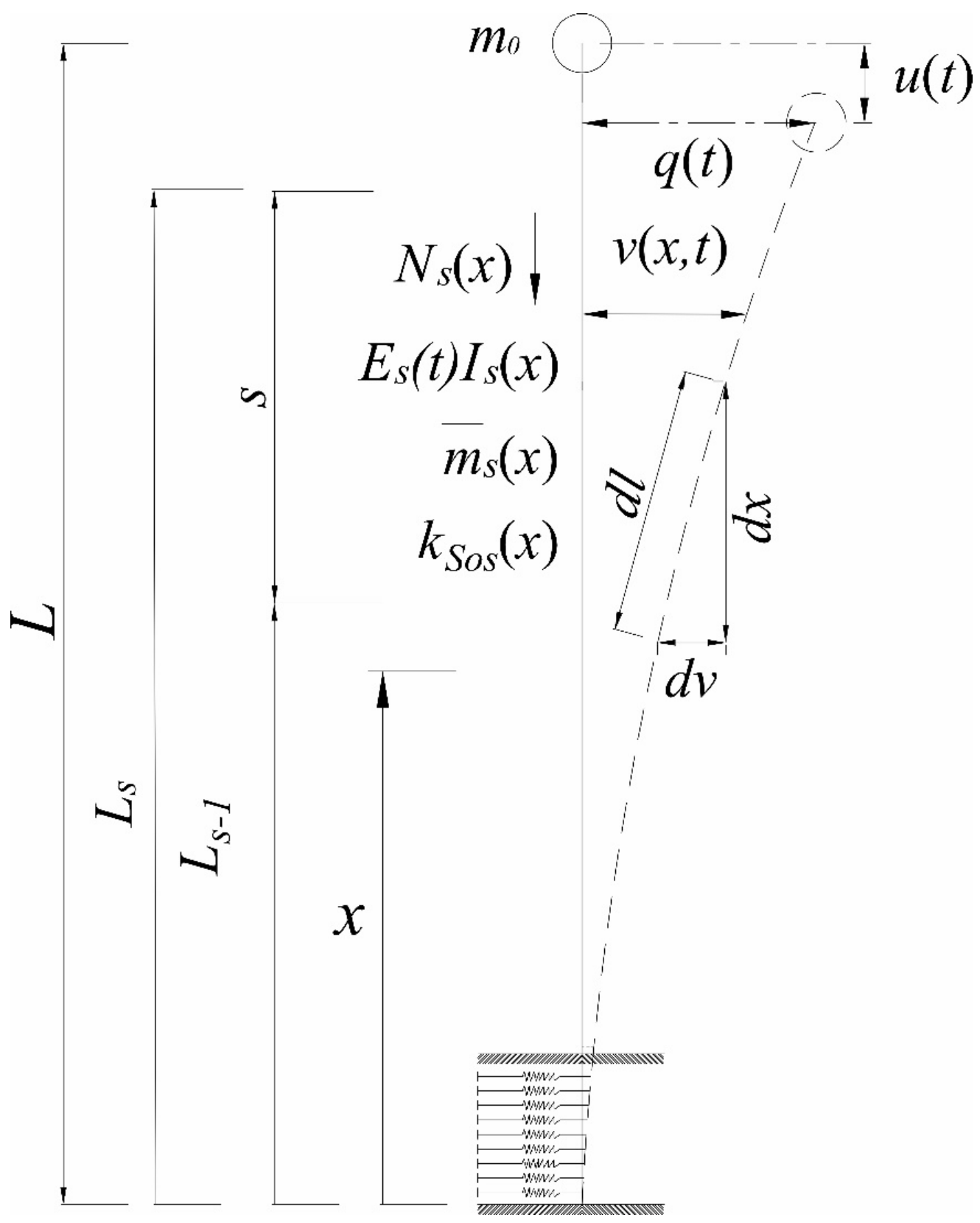

Figure 4. Mathematical model of undamped free vibrations.

To approximate the motion of the system in Figure 4 using an SDOF model, it was assumed that the system deflected in a single manner (or shape) that was adequately chosen to represent the vibration mode considered. The shape function describing this deflection is defined as $\phi(x)$, where $x$ is an independent variable representing the location along the height of the tower and the amplitude of the motion is represented by the generalized coordinate $q(t)$. This generalized coordinate was conveniently adopted as the displacement of the tip of the tower. The shape function was then obtained by calculating the following dimensionless ratio:

$\phi(x)=\frac{v(x, t)}{q(t)}$.

The equation of motion of this generalized system could be conveniently formulated using Hamilton's principle. Hence, the external virtual work done by the forces of inertia $\left(W_{E I N}\right)$ could be expressed as 
$W_{E I N}=-\sum_{s=1}^{n} \int_{L_{s-l}}^{L_{s}} \bar{m}_{s}(x) \ddot{v}(x, t) \delta v(x, t) d x$

The internal virtual work done by the flexural deformation $\left(W_{I F L}(t)\right)$ is given by

$W_{I F L}(t)=\sum_{s=1}^{n} \int_{L_{s-1}}^{L_{s}} E_{s}(t) I_{s}(x) v^{\prime \prime} \delta v^{\prime \prime} d x$

and the work done by the deformation of the foundation springs $\left(W_{I K m}\right)$ is given by

$W_{I K m}=\sum_{s=1}^{n} \int_{L_{s-1}}^{L_{s}} k_{S o s}(x) v(x, t) \delta v(x, t) d x$.

To calculate the work done by the axially directed normal force, whose direction and amplitude remained unchanged during the response, it was necessary to evaluate the vertical component of the motion of the tower tip $(u(t))$. An infinitesimal element $d l$ of the curved bar was used to determine this axial displacement. The shortening of the axis owing to this axial displacement could be expressed as

$d l-d x=\sqrt{d x^{2}-d v^{2}}-d x=d x \sqrt{1+\left(\frac{d v}{d x}\right)^{2}}-d x$

Taking the binomial expansion and considering the higher-order terms to be smaller than the first-order term, the initial series can be reduced. Thus, Eq. (27) can be written in a more compact form as

$d l-d x=d x\left[1+\frac{1}{2}\left(\frac{d v}{d x}\right)^{2}\right]-d x=\frac{1}{2}\left(\frac{d v}{d x}\right)^{2} d x$

Therefore, the total displacement $u(t)$ along the column can be obtained by integrating Eq. (28):

$u(t)=\frac{1}{2} \int_{0}^{L} v^{\prime}(x, t)^{2} d x$ and $\delta u=\int_{0}^{L} v^{\prime}(x, t) \delta v^{\prime}(x, t) d x$

Thus, the potential energy of the axial load $N_{s}(x)$ can be derived from

$W_{E N}=\sum_{s=1}^{n} \int_{L_{s-1}}^{L_{s}} N_{s}(x) v^{\prime}(x, t) \delta v^{\prime}(x, t) d x$

and the external and internal virtual work obeys the following relations:

$W_{E}=W_{I}$, or

$-\sum_{s=1}^{n} \int_{L_{s-1}}^{L_{s}} \bar{m}_{s}(x) \ddot{v}(x, t) \delta v(x, t) d x+\sum_{s=1}^{n} \int_{L_{s-1}}^{L_{s}} N_{s}(x) v^{\prime}(x, t) \delta v^{\prime}(x, t) d x+$

$\sum_{s=1}^{n} \int_{L_{s-1}}^{L_{s}} E_{s}(t) I_{s}(x) v^{\prime \prime} \delta v^{\prime \prime} d x+\sum_{s=1}^{n} \int_{L_{s-1}}^{L_{s}} k_{S o s}(x) v(x, t) \delta v(x, t) d x$,

where

$v^{\prime}(x)=\frac{\partial v(x, t)}{\partial x}, v^{\prime \prime}(x)=\frac{\partial^{2} v(x, t)}{\partial x^{2}}, \dot{v}(t)=\frac{\partial v(x, t)}{\partial t}, \ddot{v}(t)=\frac{\partial^{2} v(x, t)}{\partial t^{2}}$. 
In Eq.(32) and (33), $v^{\prime}(x)$ and $v^{\prime \prime}(x)$ represent the first- and second-order derivatives, respectively, of the virtual work done with respect to the independent variable of the lateral displacement, whereas $\dot{v}(t)$ and $\ddot{v}(t)$ represent the first- and second-order derivatives, respectively, of the virtual work done with respect to the time elapsed during the lateral displacement. The real and virtual displacements and their derivatives, expressed as functions of generalized coordinates, as well as the shape functions used to represent the considered vibration modes, can be calculated using the following set of equations:

$v(x, t)=\phi(x) q(t) ; \quad \dot{v}(x, t)=\phi(x) \dot{q}(t) ; \quad \delta v^{\prime}(x, t)=\phi^{\prime}(x) \delta q(t) ; \quad \dot{q}(t)=\frac{\partial q(t)}{\partial t}$

$v^{\prime}(x, t)=\phi^{\prime}(x) q(t) ; \quad \ddot{v}(x, t)=\phi(x) \ddot{q}(t) ; \quad \delta v^{\prime \prime}(x, t)=\phi^{\prime \prime}(x) \delta q(t) ; \ddot{q}(t)=\frac{\partial^{2} q(t)}{\partial t^{2}}$.

$v^{\prime \prime}(x, t)=\phi^{\prime \prime}(x) q(t) ; \quad \delta v(x, t)=\phi(x) \delta q(t) ; \quad \delta \dot{v}(x, t)=\phi(x) \delta \dot{q}(t) ;$

Substituting the appropriate terms from Eq. (34) into Eq. (32) yields

$\left[\begin{array}{l}\left(\sum_{s=1}^{n} \int_{L_{s-1}}^{L_{s}} \bar{m}_{s}(x) \phi(x)^{2} d x\right) \ddot{q}(t)+\left(\sum_{s=1}^{n} \int_{L_{s-1}}^{L_{s}} E_{S} I_{S}(x) \phi^{\prime \prime}(x)^{2} d x\right) q(t)- \\ \left(\sum_{s=1}^{n} \int_{L_{s-1}}^{L_{s}} N_{s}(x) \phi^{\prime}(x)^{2} d x\right) q(t)+\left(\sum_{s=1}^{n} \int_{L_{s-1}}^{L_{s}} k_{S o s}(x) \phi(x)^{2} d x\right) q(t)\end{array}\right] \delta q(t)=0$.

Because the variation $\delta q(t)$ can assume any value, this forces the term in brackets to become zero. Therefore, it can be rewritten as

$M \ddot{q}(t)+\left[K_{0}(t)-K_{g}+K_{S o}\right] q(t)=0$,

where the generalized mass $M$ of the system, including the mass at the tip, is given by

$M=\left(\sum_{s=1}^{n} \int_{L_{s-1}}^{L_{s}} \bar{m}(x) \phi(x)^{2} d x\right)+m_{0}$.

The generalized conventional stiffness $K_{0}(t)$ is given by

$K_{0}(t)=\sum_{s=1}^{n} \int_{L_{s-1}}^{L_{s}} E_{s}(t) I_{s}(x) \phi^{\prime \prime}(x)^{2} d x$

whereas the geometric stiffness $K_{g}$ becomes

$K_{g}=\sum_{s=1}^{n} \int_{L_{s-1}}^{L_{s}} N_{s}(x) \phi^{\prime}(x)^{2} d x$

where $N(x)$ denotes a function of the normal force, and the elastic stiffness of the spring $\left(K_{\text {so }}\right)$ is given by

$K_{S o}=\sum_{s=1}^{n} \int_{L_{s-1}}^{L_{s}} k_{S o s}(x) \phi(x)^{2} d x$.

The analytical formulation described above is similar to that of Rayleigh [15], who assumed that an infinitedegree-of-freedom system could be replaced by an SDOF system to estimate the frequency and buckling load. For example, Simão (2017) used the principles set forth by Rayleigh to evaluate the critical buckling loads of columns under the influence of shear. Leissa (2005) claimed that the precision achieved by applying this method depends solely on the form of the function used to represent the free vibration mode; if the exact shape is employed, the exact corresponding frequency is generated. Scheble et al. (2003) asserted that the classical Rayleigh-Ritz method requires $a$ 
priori admissibility of the shape function to satisfy the underlying variational principle. However, it is difficult to satisfy this requirement for a complex structure. Scheble et al. (2003) also noted that although diverse approaches have been used to determine the natural frequencies and normal vibration modes of large structures, they generally involve strategies for dividing structures into assemblages of finite components or substructures.

The underlying concept of both Rayleigh's method and the analytical method proposed in this paper is a simplified form of the principle of energy conservation in mechanical systems. Of some relevance here is the suggestion by Temple and Bickley (1933) that the fundamental principles developed by Rayleigh are applicable to both linear and nonlinear continuous systems with finite or infinite degrees of freedom. The advantage of the method proposed in this paper is its applicability to the determination of the fundamental vibration period and analysis of the stability of elastic systems with sufficient precision for engineering applications.

\subsection{Mathematical modeling of a practical problem}

The system is considered to be under the normal gravitational forces induced by the distributed masses (the selfweight, ladder, and cables) along the length of the tower, as well as the lumped masses at the tip of the tower (the antennae and platform). In addition, the following well-known trigonometric function (Timoshenko and Gere, 1961; Challamel and Hellesland, 2013) is assumed to be valid throughout the domain of the structure:

$$
\phi(x)=1-\cos \left(\frac{\pi x}{2 L}\right)
$$

where $x$ represents the location of the calculation, measured upwards from the base along the tower height, and $L$ is the total length (or height) of the column. To obtain an analytical solution to the present problem, the trigonometric function in Eq. (41) was considered to be a function of $x$ only, thereby effectively reducing the cantilever column to an SDOF system. Shang et al. (2017) and Pramod et al. (2017) employed trigonometric equations in their analysis to define a shape function for the free vibration of planar elements, having the first one worked in the context of the Unit Partition Method. Ding, Tan, and Dowell (2017); Masjedi and Maheri (2017); and Pradhan and Chakraverty (2017) also used trigonometric equations to account for beam vibrations under different operating conditions. In the case of the vibration of a cantilever column (fixed at its base but free at its tip), the shape function in Eq. (41) satisfies the boundary conditions, i.e., when $x=L$ (at the free extremity of the column), $\phi(L)=1$, and when $x=0$ (at the base), $\phi(0)=$ 0 . The use of Eq. (41) as the shape function for an actual structure with varying geometry was validated by Wahrhaftig (2017), by comparing the results obtained using this function with those obtained using the FEM and other mathematical functions.

Therefore, as described in Section 4.1, the dynamic properties of the system can be computed. The conventional elastic/viscoelastic stiffness can be expressed as shown in Eq. (38), where, for a given segment $s$ of the structure, $E_{s}(t)$ is the time-dependent viscoelastic modulus of the material; $I_{s}(x)$ is the variable moment of inertia of a given cross-section along the segment in relation to the considered movement, obtained by interpolating the already homogenized previous and following cross-sections (if the moment of inertia is constant, it is simply $l_{s}$ ); $k_{0 s}(t)$ is a temporal stiffness term; $K_{0}(t)$ is the final conventional time-varying stiffness; and $n$ is the total number of segments based on the geometry of the structure. In Eq. (38), the variable $t$ obviously vanishes for a material with purely elastic timeindependent behavior.

The geometric stiffness, as shown in Eq. (39), can be expressed as a function of the axial load, including the selfweight, as follows:

$$
K_{g}\left(m_{0}\right)=\sum_{s=1}^{n} \int_{L_{s-1}}^{L_{s}}\left[N_{0}\left(m_{0}\right)+\sum_{j=s+1}^{n} N_{j}+\bar{m}_{s}(x)\left(L_{s}-x\right) g\right] \phi^{\prime}(x)^{2} d x,
$$

where $K_{\mathrm{g}}\left(m_{0}\right)$ is the total geometric stiffness of the structure with $n$ segments, $N_{0}\left(m_{0}\right)$ is the concentrated force at the top of the structure as a function of the mass $m_{0}$ at the tip, and $N_{j}$ is the normal force developed in the upper segments, given by

$$
N_{0}\left(m_{0}\right)=m_{0} g \text { and } N_{j}=\int_{L_{s-1}}^{L_{s}} \bar{m}_{s}(x) g d x,
$$


where $m_{0}$ is the lumped mass at the tip of the element joint and $\bar{m}_{s}(x)$ is the mass per unit length. The total generalized mass is thus given by

$M\left(m_{0}\right)=m_{0}+m$,

considering that

$m=\sum_{s=1}^{n} \int_{L_{s-1}}^{L_{s}} \bar{m}_{s}(x) \phi(x)^{2} d x$, with $\bar{m}_{s}(x)=A_{s}(x) \rho_{s}$,

where $\bar{m}_{s}(x)$ represents the distributed mass in each segment $s$. Therefore, $\bar{m}_{s}(x)$ is the mass per unit length and $m$ is the generalized mass of the system based on the density of the material. If the cross-sectional area of the cantilever column is constant over a given interval, $A_{s}(x)$ can be simplified to $A_{s}$, and the distributed mass also becomes constant. Similarly, if $m_{0}$ does not vary, all the parameters that depend on it become constant.

One way of considering the effects of the soil on the vibration analysis of the system involves regarding the soil as a series of vertically distributed springs that generate a restorative force. If $k_{\text {sos }}(x)$ denotes the spring parameter, the effective soil stiffness (as a function of $x$ along the length of the column) can be generally defined as

$K_{S o}=\sum_{s=1}^{n} \int_{L_{s-l}}^{L_{s}} k_{S o s}(x) \phi(x)^{2} d x$, with $k_{\text {Sos }}(x)=S_{o p s} D_{s}(x)$

where $K_{s_{o}}$ is an elastic characteristic given by the sum of $k_{s o s}(x)$ along the foundation depth $D_{s}(x)$ (dependent on the geometry of the foundation) and the soil parameter $S_{\text {ops. }}$. In this study, $S_{o p s}$ was considered to be constant for each layer of soil, which is not necessarily the case. The variables $s$ and $n$ in Eq. (46) are as previously defined.

Considering the normal force to be positive, the overall structural stiffness can be obtained by

$K\left(m_{0}, t\right)=K_{0}(t)-K_{g}\left(m_{0}\right)+K_{S o}$

Finally, the natural frequency can be expressed as a function of time and the tip mass as follows:

$\omega\left(m_{0}, t\right)=\sqrt{\frac{K\left(m_{0}, t\right)}{M\left(m_{0}\right)}}(r d / s) \therefore f\left(m_{0}, t\right)=\frac{\omega\left(m_{0}, t\right)}{2 \pi}($ Hertz $)$.

It is important to observe that the conventional stiffness fundamentally depends on the elastic/viscoelastic/plastic behavior of the material, whereas the geometric stiffness is predominantly a function of the normal force acting on the system, including the self-weight of the structural element. All problems are more or less nonlinear from a geometric viewpoint. Hence, Eq. (47), which includes Eq. (42), automatically captures the level of nonlinearity of the problem in its solution.

The mathematical procedure described above was used in this study to determine not only the frequency of the structure but also the critical buckling load. The relevant criterion for determining the critical buckling load of the dynamic structure was established by assuming zero frequency at the instant at which the structure lost its stiffness. The load was thus expressed as a function of the lumped mass at the free extremity of the column, $N\left(=N\left(m_{0}\right)\right.$, Eq. (43)). To introduce creep into the analysis, it was necessary to use a model that accurately represented the viscoelastic behavior of the concrete. After introducing creep, the frequency and critical buckling load become functions of time, owing to the variation of the modulus of elasticity of the structure with time. Therefore, the frequency can be expressed in terms of the elapsed time and the mass at the top of the cantilever column (Eq. (48)).

For a column with constant elastic/viscoelastic properties along its length, a unique moment of inertia, and a uniform material density, all the previous integrals can be taken over a single interval covering the entire height of the column. Thus, the final equation for calculating the first undamped resonance frequency $(\mathrm{Hz})$ can be expressed in the form of Eq. (49), which can be obtained by substituting Eqs. (44) and (47) into Eq. (48). Note that the soil-structure interaction is not included in this formulation. All the previous observations regarding creep remain valid, including the correspondence between the critical buckling load and zero frequency, which occurs at an arbitrary time. 
$f\left(m_{0}, t\right)=\frac{1}{2 \pi}\left(\frac{\frac{\pi^{4}}{32} \frac{E^{\prime}(t) I^{\prime}}{L^{3}}+\left[\frac{\pi^{2}}{16}\left(\frac{2 m_{0}+\bar{m}^{\prime} L}{L}\right)-\frac{1}{4} \bar{m}^{\prime}\right] g}{m_{0}+\frac{3 \pi-8}{2 \pi} L \bar{m}^{\prime}}\right)^{\frac{1}{2}}$,

where $L$ is the length of the column, $g$ is the acceleration due to gravity, $E(t)^{\prime}$ is the viscoelastic modulus of the material, and $I^{\prime}$ is the moment of inertia, which must be homogenized and reduced from its full value to account for the presence of steel reinforcements in the RC and the developed cracks within the structure. In Eq. (49), the conventional portion of the column stiffness, including the modulus of viscoelasticity, is to the left of the addition sign in the numerator, whereas the geometric portion of the stiffness is to the right. In this equation, the force concentrated at the free end of the column (mass $m_{0}$ ) is considered in addition to the self-weight through the parameter $\bar{m}^{\prime}($ mass distributed per unit length), and both are multiplied by the acceleration due to gravity.

Based on Eq. (49), both the geometric and material nonlinear analyses, which involve reducing the flexural bending and considering the effects of creep, can be performed in a single mathematical operation, which also accounts for the effects of the normal force, without requiring complex computational tools and/or iterative calculations. Further details on the development of this specific analytical procedure have been provided in a previous report (Wahrhaftig et al., 2013).

\subsection{Creep calculation}

To determine the effects of creep, the initial zero-load condition at time $t_{0}$ was assumed to extend over 28 days from the time of production under standard conditions, while the humidity rose to $70 \%$. The parameters listed in Table 2 were used for the analysis. The area of the concrete was calculated using the average of the external and internal diameters of the superstructure (tower), i.e., $D=733.3 \mathrm{~mm}$ and $d=446.7 \mathrm{~mm}$, respectively; thus, the perimeter in contact with the environment $(\pi D)$ was $2300 \mathrm{~mm}$.

The other relevant parameter values were set as follows: $\varphi_{\mathrm{RH}}=1.257, h_{0}=230.64 \mathrm{~mm}, b\left(f_{\mathrm{cm}}\right)=2.308$, $B\left(t_{0}\right)=0.488, \varphi_{0}=0.266, \alpha_{1}=0.748, \alpha_{2}=0.920, \alpha_{3}=0.813$, and $B_{H}=564.112$. The deformation and temporal modulus of elasticity were computed by inputting these values into Eqs. (12) and (13), respectively. The results are shown in Figure 5. 


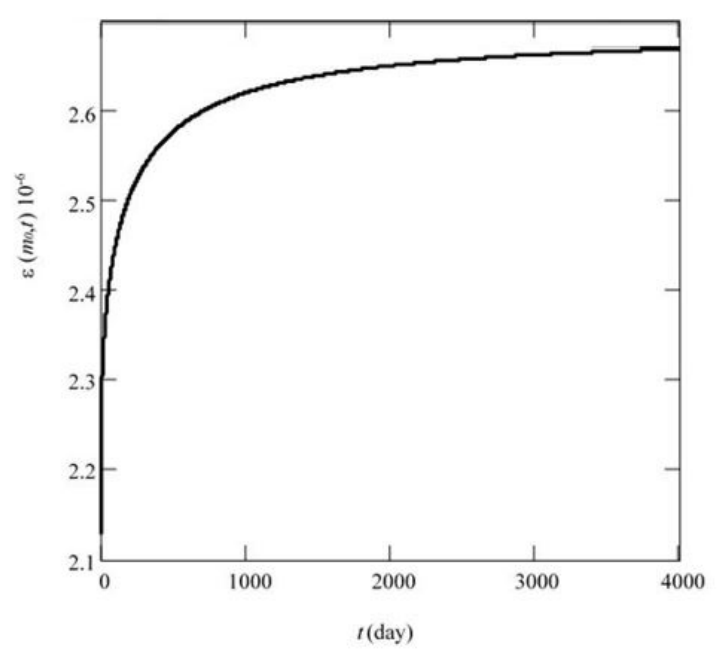

(a) Structural deformation versus time

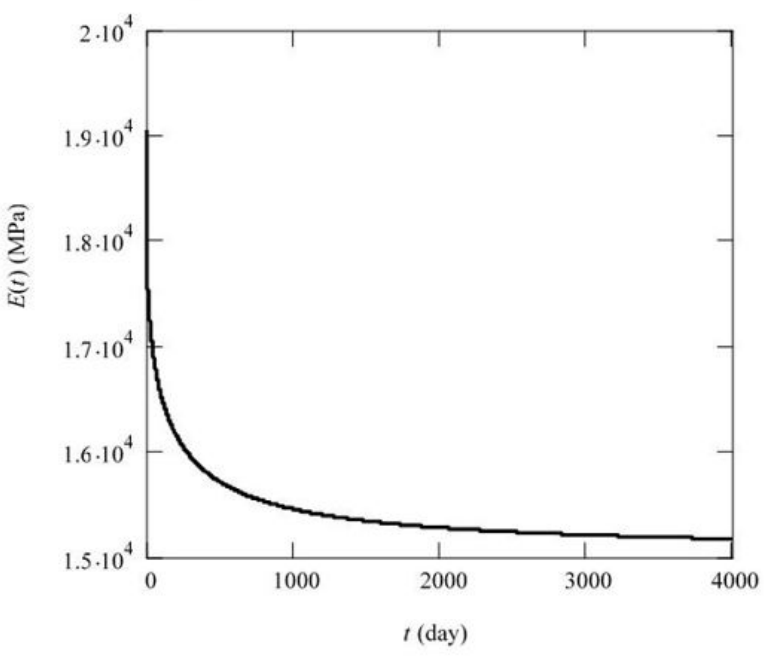

(b) Temporal modulus of elasticity versus time

Figure 5. Variations of the structural deformation and modulus of elasticity with time.

\subsection{Calculation of generalized mass}

Hereafter, Roman numeral subscripts are used to denote the tower segments. The generalized mass can be calculated by taking the following integrals:

$m_{l}=\int_{0}^{L_{l}} m_{I}(x) \phi(x)^{2} d x$, where $m_{I}(x)=A_{I}(x) \rho_{I} ;$

$m_{2}=\int_{L_{1}}^{L_{2}} m_{I I} \phi(x)^{2} d x$, where $m_{2}=\int_{L_{I}}^{L_{2}} m_{I I} \phi(x)^{2} d x$

$m_{3}=\int_{L_{2}}^{L_{3}} m_{I I I} \phi(x)^{2} d x$, with $m_{I I I}=A_{3} \rho+\bar{m}_{e}$

$m_{4}=\int_{L_{3}}^{L_{4}} m_{I V}(x) \phi(x)^{2} d x$, where $m_{I V}=A_{4}(x) \rho+\bar{m}_{e}, A_{4}(x)=\frac{A_{4}-A_{3}}{L_{4}-L_{3}}\left(x-L_{3}\right)+A_{3} ;$

and $m_{5}=\int_{L_{4}}^{L} m_{V} \phi(x)^{2} d x$, where $m_{V}=A_{5} \rho+\bar{m}_{e}$. 
Summing the above integrals yields the generalized distributed mass:

$m=\sum_{s=1}^{5} m_{s}$

The total generalized mass of the structure is given by Eq. (52), which is a modification of Eq. (44) that accounts for mass variation. For $m_{0}$ in Table 2, the total generalized mass of the structure considered in the present study is $7848.06 \mathrm{~kg}$.

$M\left(m_{0}\right)=m_{0}+m$

\subsection{Calculation of generalized geometric stiffness}

To compute the generalized geometric stiffness, it was necessary to determine the normal forces within the parts defined by the geometry. From top to bottom along the length of the structure, the normal forces are as follows:

$$
\begin{aligned}
& N_{0}\left(m_{0}\right)=m_{0} g, \\
& N_{5}=\int_{L_{4}}^{L} m_{V} g d x, \\
& N_{4}=\int_{L_{3}}^{L_{4}} m_{I V}(x) g d x, \\
& N_{3}=\int_{L_{2}}^{L_{3}} m_{I I I} g d x, \\
& N_{2}=\int_{L_{I}}^{L_{2}} m_{I I} g d x, \text { and } \\
& N_{I}=\int_{0}^{L_{l}} m_{I}(x) g d x,
\end{aligned}
$$

where $g$ is the gravitational acceleration. Summing these six terms yields the total normal force $N$ :

$$
N\left(m_{0}\right)=N_{0}\left(m_{0}\right)+\sum_{s=1}^{5} N_{s}
$$

The geometric stiffness can then be calculated as follows:

$$
\begin{aligned}
& K_{g 5}\left(m_{0}\right)=\int_{L_{4}}^{L}\left[N\left(m_{0}\right)+m_{V}(L-x) g\right] \phi^{\prime}(x)^{2} d x, \\
& K_{g 4}\left(m_{0}\right)=\int_{L_{3}}^{L_{4}}\left[N\left(m_{0}\right)+N_{5}+m_{I V}(x)\left(L_{4}-x\right) g\right] \phi^{\prime}(x)^{2} d x, \\
& K_{g 3}\left(m_{0}\right)=\int_{L_{2}}^{L_{3}}\left[N\left(m_{0}\right)+N_{5}+N_{4}+m_{I I I}\left(L_{3}-x\right) g\right] \phi^{\prime}(x)^{2} d x,
\end{aligned}
$$




$$
\begin{aligned}
& K_{g 2}\left(m_{0}\right)=\int_{L_{l}}^{L_{2}}\left[N\left(m_{0}\right)+N_{5}+N_{4}+N_{3}+m_{I I}\left(L_{2}-x\right) g\right] \phi^{\prime}(x)^{2} d x, \\
& K_{g I}\left(m_{0}\right)=\int_{0}^{L_{l}}\left[N\left(m_{0}\right)+N_{5}+N_{4}+N_{3}+N_{2}+m_{I}(x)\left(L_{l}-x\right) g\right] \phi^{\prime}(x)^{2} d x .
\end{aligned}
$$

The generalized geometric stiffness $K_{\mathrm{g}}\left(m_{0}\right)$ of the structure was obtained by summing these five terms:

$K_{g}\left(m_{0}\right)=\sum_{s=1}^{5} K_{g s}\left(m_{0}\right)$

Based on Eq. (56) and the value of $m_{0}$ in Table $2, K_{\mathrm{g}}\left(m_{0}\right)$ was computed to be $2.631 \mathrm{kN} / \mathrm{m}$ for the present structure.

\subsection{Calculation of generalized conventional stiffness}

The conventional elastic stiffness components can be expressed as

$$
\begin{aligned}
& K_{0 I}=\int_{0}^{L_{l}} E_{f} I_{I}(x) \phi^{\prime \prime}(x)^{2} d x, \\
& K_{02}=\int_{L_{1}}^{L_{2}} E_{f} I_{2} \phi^{\prime \prime}(x)^{2} d x, \\
& K_{03}(t)=\int_{L_{2}}^{L_{3}} E(t) I_{3} \phi^{\prime \prime}(x)^{2} d x, \\
& K_{04}(t)=\int_{L_{3}}^{L_{4}} E(t) I_{4}(x) \phi^{\prime \prime}(x)^{2} d x, \text { and } \\
& K_{05}(t)=\int_{L_{4}}^{L} E(t) I_{5} \phi^{\prime \prime}(x)^{2} d x .
\end{aligned}
$$

The summation of the above components yields the generalized elastic stiffness:

$$
K_{0}(t)=\sum_{s=1}^{5} K_{0 s}(t)
$$

Based on Eq. (58), the initial generalized elastic stiffness of the present structure was found to be $9.471 \mathrm{kN} / \mathrm{m}$. Note that no creep occurs in the foundation; thus, the modulus of elasticity $\left(E_{f}\right)$ is not a temporal function. However, $E(t)$ represents the material behavior of the tower, and it can be described using Eq. (13), implying that $E_{c}\left(t_{0}\right)=E_{c}\left(t_{28}\right)=$ $E_{c}$.

\subsection{Calculation of the generalized soil-spring stiffness}

For the specific case under consideration, the elastic soil parameter can be set to $S_{o p}=2668.93 \mathrm{kN} / \mathrm{m}^{3}\left(S_{o p}=S_{o p 1}=\right.$ $\left.S_{o p 2}\right)$. The distributed spring stiffnesses in the first and second segments can then be expressed as $k_{I}(x)=S_{o p 1} D_{I}(x)$ and $k_{2}=S_{o p 2} D_{2}$, respectively. Using the following equation, the generalized spring stiffness $K_{S o}$ was computed to be 1.123 $\mathrm{kN} / \mathrm{m}$ :

$$
K_{S o}=\int_{0}^{L_{l}} k_{I}(x) \phi(x)^{2} d x+\int_{L_{l}}^{L_{2}} k_{2} \phi(x)^{2} d x
$$


Finally, the generalized total stiffness of the structure was obtained as the algebraic sum of the different contributors, i.e., a function of two variables in accordance with Eq. (47). At $t_{0}$ and for the value of $m_{0}$ in Table 2, the generalized total stiffness was found to be $7.363 \mathrm{kN} / \mathrm{m}$.

\subsection{Frequency calculation}

The frequency of the first vibration mode was computed numerically using Eq. (48), which is a function of the mass at the top and time and considers creep. Based on the parameter values in Table 2, the frequency of the first mode without considering creep was found to be $0.160 \mathrm{~Hz}$. The corresponding value computed by performing linear analysis without considering the geometric stiffness was $0.185 \mathrm{~Hz}$. By contrast, the frequency varies with time when creep is included, as shown in Figure 6. At 4000 days after the commencement of loading, the frequency decreased toward an asymptotic value of $0.147 \mathrm{~Hz}$, illustrating the need for structural stability verification. Discarding the geometric stiffness, that frequency is $0.173 \mathrm{~Hz}$.

To apply Eq. (49) directly in an analysis using $E^{\prime}, l^{\prime}$, and $\bar{m}^{\prime}$ as the unique modulus of elasticity, moment of inertia, and unit mass of the structural system, respectively, it is necessary to employ a criterion to weight the geometric properties of the structure.

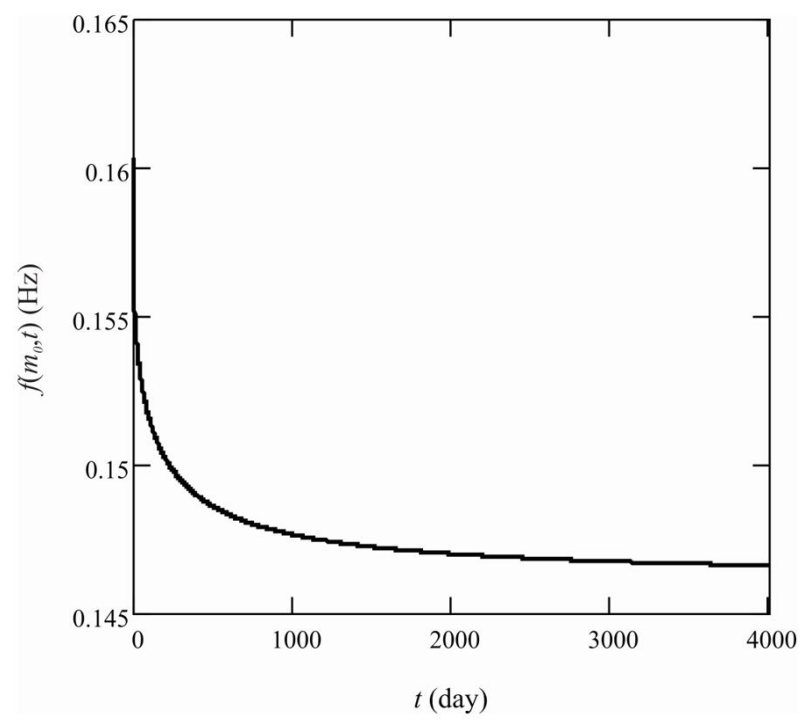

Figure 6. Variation of the fundamental natural frequency of the structure with time.

One possible weighting scheme is shown in Eq. (60), where $A 1$ and $I 1$ denote the area and moment of inertia, respectively, calculated using the average diameter of the body structure, and $A 2$ and $I 2$ denote the area and moment of inertia, respectively, calculated using the average diameter of the foundation. $\rho, \rho 1, E$ and $E 1$ are the density and modulus of elasticity of the pole and foundation.

$A^{\prime}=\frac{A 1 \cdot 40+A 2 \cdot 6}{46}, I^{\prime}=\frac{I 1 \cdot 40+I 2 \cdot 6}{46} F_{\text {hsave }}, E^{\prime}=\frac{E \cdot 40+E 1 \cdot 6}{46}$, and $\rho^{\prime}=\frac{\rho \cdot 40+\rho 1 \cdot 6}{46} \therefore \bar{m}^{\prime}=A^{\prime} \cdot \rho^{\prime}$,

Considering the mass of the structure and foundation shaft, the weighted parameters for the present case are as follows: area $A^{\prime}=0.289 \mathrm{~m}^{2}$, moment of inertia $I^{\prime}=0.0138 \mathrm{~m}^{4}$, homogenizing factor $F_{\text {hsave }}=1.062$, modulus of elasticity $E^{\prime}=18615.81 \mathrm{MPa}$, and density $\rho^{\prime}=2586.957 \mathrm{~kg} / \mathrm{m}^{3}$. Therefore, the geometric and material nonlinear frequency was calculated using the weighted parameters to be approximately $0.120 \mathrm{~Hz}$ at zero time and $0.101 \mathrm{~Hz}$ after 400 days in operation. It is also possible to consider creep in this calculation by using the temporal modulus of elasticity, as estimated using Eq. (13), and simply considering $E^{\prime}$ as $E_{c}\left(t_{0}\right)=E_{c}\left(t_{28}\right)$ to obtain $E^{\prime}(t)$ for Eq. (49). 


\subsection{Calculation of critical buckling load}

In addition to the changing frequency of the structure, the variation of the mass $m_{0}$ at the top of the tower causes the force acting at the top to vary (in accordance with Eq. (61)). Thus, the critical buckling load ( $N_{\text {buck }}$ ) at zero frequency can be defined as

$N_{0}\left(m_{0}\right)=m_{0} g$, and $f_{c}\left(m_{0}, t\right)=\left.0 \Rightarrow N_{0}\left(m_{0}\right)\right|_{f_{c}\left(m_{0}, t\right)=0}=N_{\text {buck }}$.

The variation of the critical buckling load with the mass $m_{0}$ at the top of the tower is shown in Figure 7; thus, the critical buckling load of the structure can be computed at any stage during its service life.

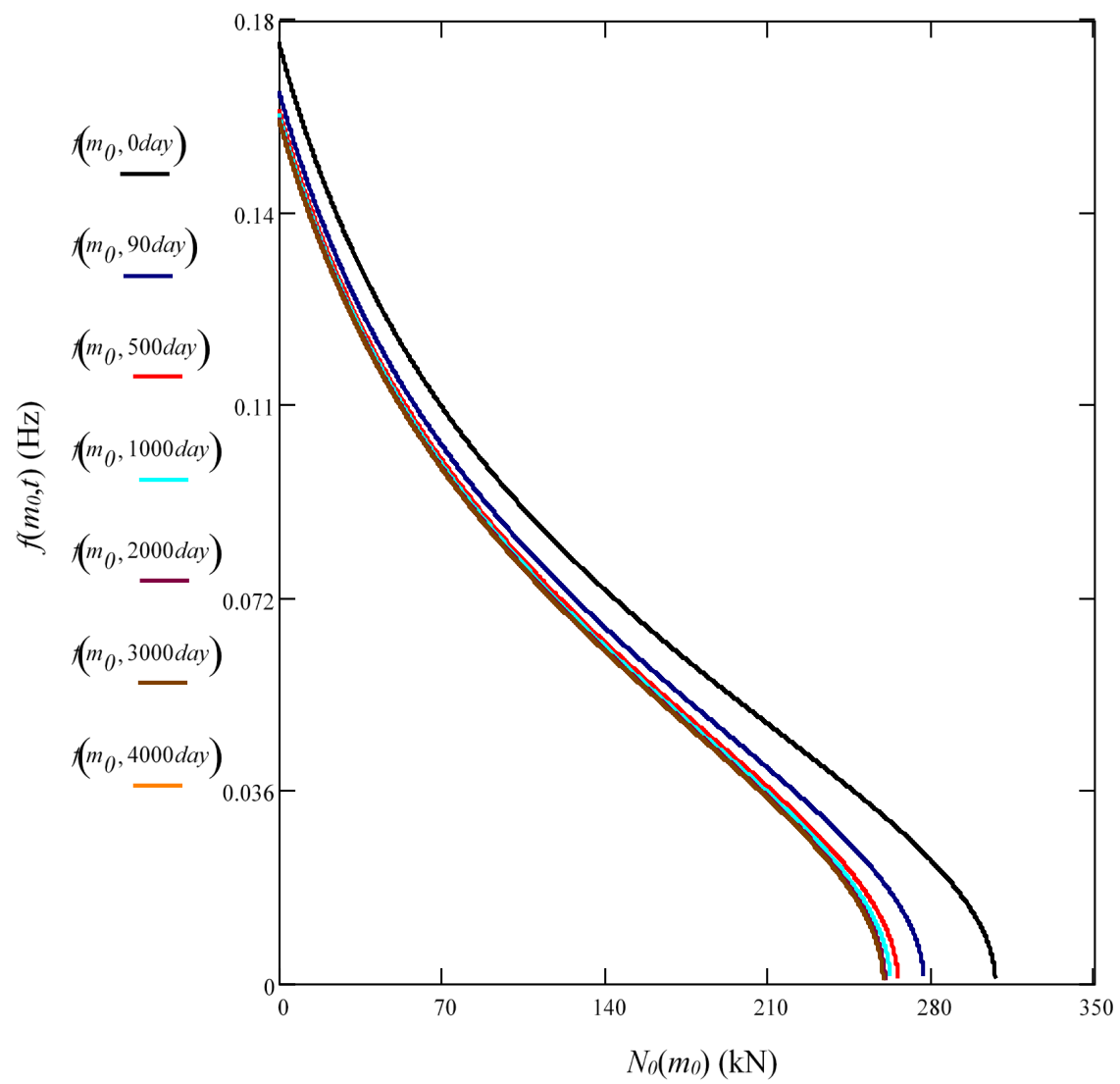

Figure 7. Variation of the critical buckling load with time.

\section{FINITE ELEMENT ANALYSIS}

It should be noted that, while the analytical solution presented in the previous Section provides a single functional form for the entire problem domain, the FEM formulation establishes interpolation functions that are restricted to the domain of each finite element. Regarding the mathematical procedure, FEM analysis represents a geometric nonlinear formulation based on a consideration of the geometric stiffness. According to Bathe and Wilson (1973), in terms of modal analysis, the relevant eigenvalues and eigenvectors can be obtained by solving the following secular equation:

$$
\left\{(K)-\left[\omega^{2}\right](M)\right\}[\Phi]=0,
$$

where $(M)$ is the mass matrix and $(K)$ is the stiffness matrix, which includes the geometric stiffness term for nonlinear cases, formulated similarly to Eq. (47). In the FEM environment, [ $\left.\omega^{2}\right]$ represents the eigenvalues and [ $\left.\Phi\right]$ represents the eigenvectors. The spring matrix is a $6 \times 6$ symmetric matrix of the spring coefficients $k_{i j}$, including all the translational and rotational degrees of freedom of a bar element. The components of this matrix are nodal springs. The mathematical development of the FEM system, as described above, is based on modal analysis performed by reducing the stiffness of the system using geometric stiffness matrix components. The importance of the geometric stiffness to the FEM solution for cases similar to that of the present study was highlighted by Armand and Lin(1993), who employed a full stiffness matrix to derive a dynamic solution for the frequency of a 30-m-tall tower. 
The buckling analysis requires the solution of another generalized eigenvalue problem. The equation governing the buckling of an assemblage of structural elements can be expressed as

$$
\left\{\left(K_{0}+K_{m}\right)-[\lambda]\left(K_{g}\right)\right\}[\psi]=0,
$$

where $[\lambda]$ is the diagonal matrix of the eigenvalues and $[\psi]$ is the matrix of the corresponding eigenvectors (mode shapes). The stiffness matrices $\left(K_{0}\right),\left(K_{m}\right)$, and $\left(K_{g}\right)$ are as previously stated.

To assess the accuracy of the proposed equations for the frequency and critical buckling load, their results were compared with those given by an FEM computational model. The considered structure was modeled using frame elements with constant or variable cross-sections, as appropriate. The forces presented in Table 1 were applied to the model with the corresponding masses. The spring factor $S_{o p}$ was assigned to the foundation frame element as a linearly distributed parameter. Only a lateral spring was used to model the foundation system, and the spring stiffness matrix was thus considered to be null at all positions corresponding to the axial and rotational degrees of freedom, while the values extrapolated from the interior of each element joint were considered to be active components of the matrix. Figure 8 shows the three-dimensional model constructed using SAP2000 (2015) structural analysis software, as well as the discretization of the structure in Figure 1 using 45 frame elements.

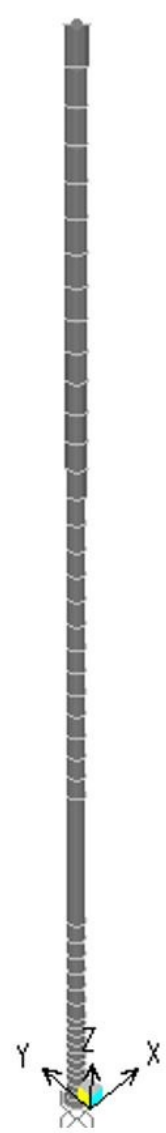

(a) $3 \mathrm{D}$ view

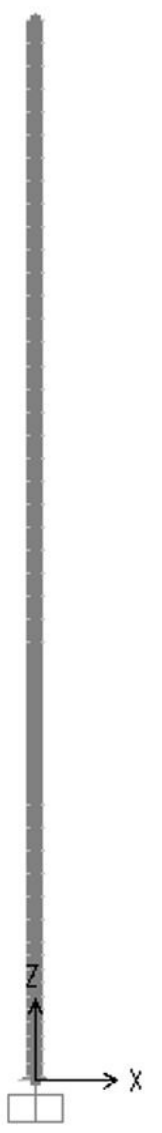

(b) $2 \mathrm{D}$ view

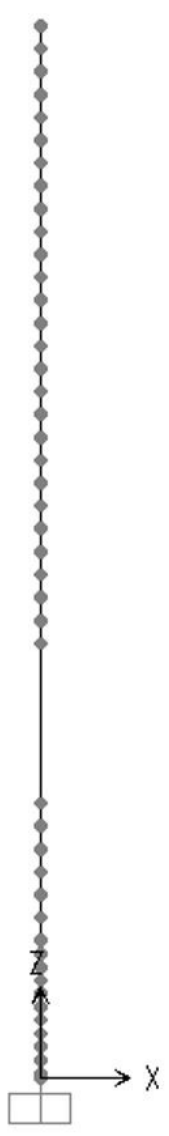

(c) Discretization

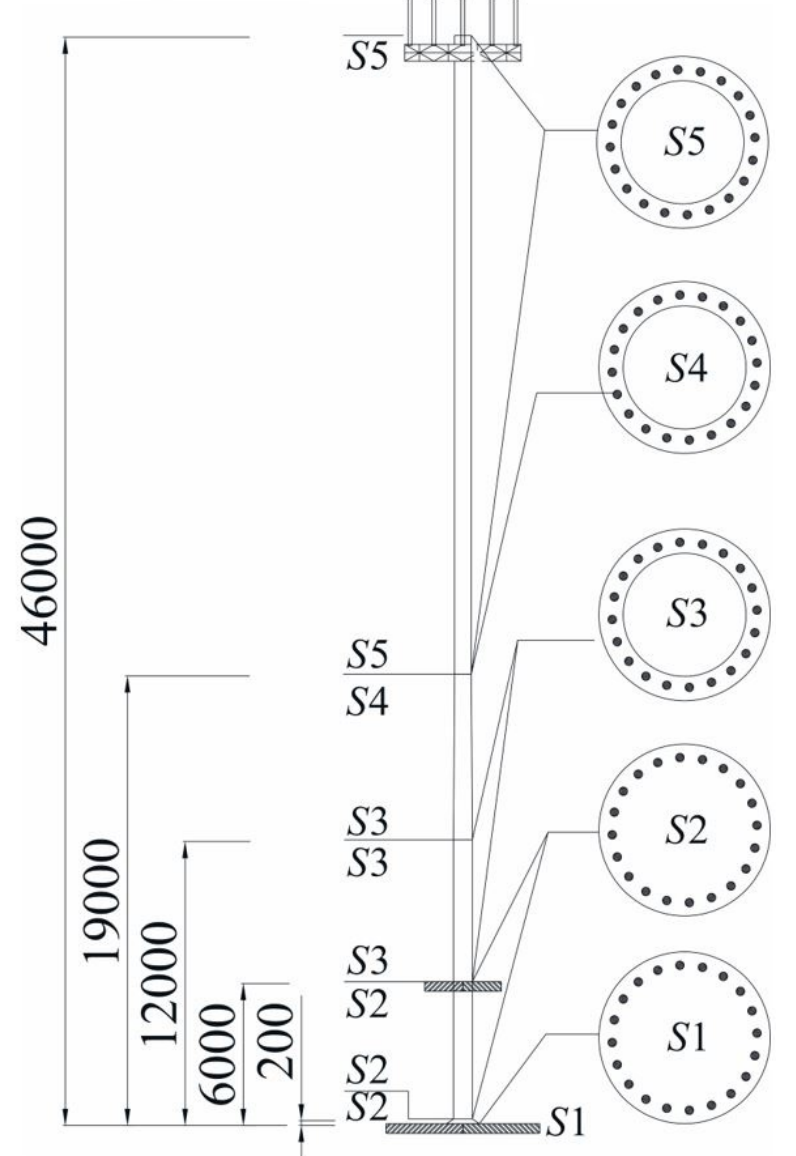

(d) Sections (heights in millimeters)

Figure 8. FEM model of the tower structure.

The rightmost panel in the figure shows the cross-sectional details of the structure, where $S$ indicates the type of section. In nonlinear problems, discretization significantly influences the results under dynamic conditions, with deviations of up to $21 \%$ observed between the results obtained by linear and nonlinear analyses (Wahrhaftig, 2013). In the present study, the natural frequency of the tower was calculated by performing nonlinear static FEM analysis, with the effects of the normal forces taken into consideration using the equations provided above. This method is regarded as a geometric nonlinear approach (SAP2000, 2015). Note that the global stiffness matrices of the structure were obtained automatically by the analysis software. The first vibration mode frequency and buckling load were computed by using the FEM and assuming an isotropic homogeneous material using the parameters employed in the analytical investigation and a Poisson's ratio of 0.2. Note that the interpolation functions commonly used in FEM equations are 
third-degree polynomials, as in the work of Wilson and Bathe (1976). By contrast, the analytical solution proposed in this paper involves a trigonometric function.

\section{RESULTS AND DISCUSSION}

Table 3 compares the results obtained using the proposed analytical procedure with those given by the FEM analysis, considering all the parameters listed in Table 2 and the creep, which was calculated by Eurocode 2 . The first vibration modes predicted by applying the proposed method via Eq. (41) and by applying the nonlinear FEM formulation via Eq. (62) are compared in Figure 9, and they are found to be in good agreement.

Table 3. Results obtained using the proposed analytical procedure and FEM analysis with respect to time.

\begin{tabular}{lcccccc}
\hline \hline Time (day) & \multicolumn{2}{c}{ Eurocode Parameter } & \multicolumn{2}{c}{ Analytical Procedure } & \multicolumn{2}{c}{ FEM } \\
\cline { 2 - 7 } & $\begin{array}{c}\text { Modulus of } \\
\text { elasticity (MPa) }\end{array}$ & $\begin{array}{c}\text { Deformation } \\
\left(\times \mathbf{1 0}^{-6}\right)\end{array}$ & $\begin{array}{c}\text { Frequency } \\
\mathbf{( H z )}\end{array}$ & $\begin{array}{c}\text { Buckling load } \\
(\mathbf{k N})\end{array}$ & $\begin{array}{c}\text { Frequency } \\
(\mathbf{H z})\end{array}$ & $\begin{array}{c}\text { Buckling load } \\
(\mathbf{k N})\end{array}$ \\
\hline 0 & 19048.674 & 2.127 & 0.160 & 307.687 & 0.155 & 263.602 \\
90 & 16615.247 & 2.439 & 0.152 & 277.126 & 0.145 & 226.278 \\
500 & 15720.566 & 2.578 & 0.149 & 265.890 & 0.141 & 212.177 \\
1000 & 15459.131 & 2.621 & 0.148 & 262.606 & 0.139 & 208.017 \\
2000 & 15282.108 & 2.652 & 0.147 & 260.383 & 0.138 & 205.189 \\
3000 & 15212.587 & 2.664 & 0.147 & 259.510 & 0.138 & 204.077 \\
4000 & 15175.347 & 2.670 & 0.147 & 259.042 & 0.138 & 203.480 \\
Variation & $20.33 \%$ & $20.33 \%$ & $8.56 \%$ & $15.81 \%$ & $11.30 \%$ & $22.81 \%$ \\
\hline \hline
\end{tabular}

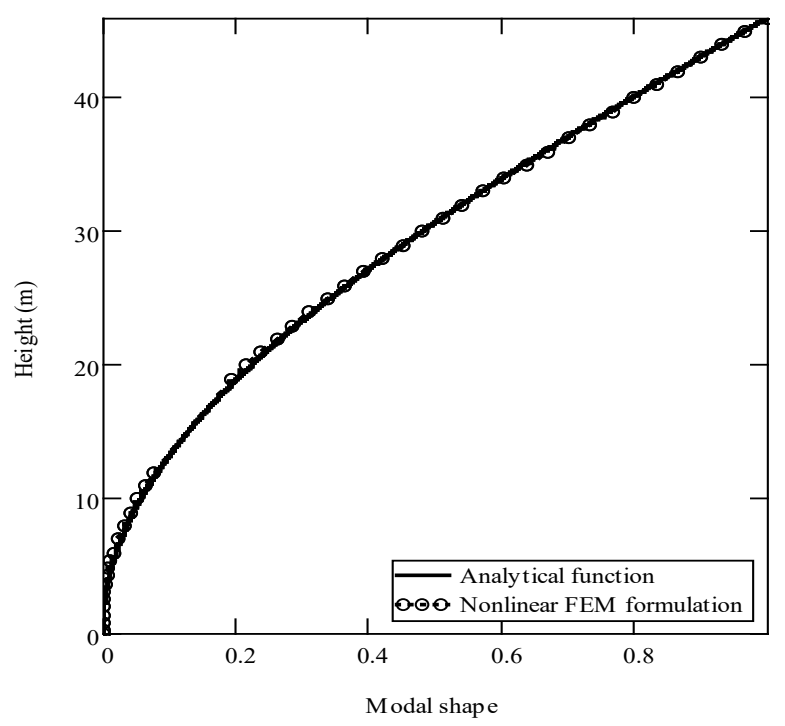

Figure 9. Vibration shapes predicted using the proposed analytical method and FEM analysis.

The vibration frequencies were computed using the proposed method and the FEM as $0.160 \mathrm{~Hz}$ and $0.155 \mathrm{~Hz}$. It was further observed that the geometric stiffness was $27.78 \%$ of the structural elastic stiffness $K_{0}$ and $24.83 \%$ of the total stiffness given by $K_{0}+K_{m}$, implying that the reduced stiffness produced by including the geometric stiffness was accompanied by a $13.30 \%$ reduction of the first natural vibration frequency. Similar FEM analysis performed by introducing the geometric stiffness yielded a frequency reduction of $14.23 \%$. The effective creep coefficient was calculated as 1.26 given by relation between deformations at the considered interval of time.

The frequency calculated by applying Eq. (49) and using weighted parameters was $0.120 \mathrm{~Hz}$ in the nonlinear case at zero time and $0.101 \mathrm{~Hz}$ at the end the time analyzed (15.83\% lower). This finding highlights the importance of applying a correction factor of 1.34 and 1.45 to obtain accurate results for 0 and 4000 days, respectively. When considering the effects of the steel reinforcement of the structure, thereby increasing the moment of inertia of the structure by an average factor of 1.06. Note that Eq. (49) does not consider the restoring action of the soil pressure when considering the spring parameters. When restoration due to the spring action is considered in the formulation, 
Eq. (49) does not have a practical form, and the frequency is overestimated. The soil stiffness accounted for roughly $12.36 \%$ of the total stiffness of the structure.

The natural frequency of the structure 4000 days after installation $(0.147 \mathrm{~Hz})$ was $8.56 \%$ lower than that at the time of installation. This result implies that, when the mean lateral loading due to wind is calculated principally as a function of the first natural frequency and the corresponding vibration mode, any frequency reduction would be critical to the dynamic behavior of the structure. The critical buckling load was estimated using the analytical process as a compressive force of $307.687 \mathrm{kN}$ at time zero, corresponding to the first natural frequency. The FEM-predicted critical buckling load under identical operating conditions was $263.602 \mathrm{kN}$. For lightly loaded telecommunication towers, the risk of buckling may be insignificant. Nevertheless, verification is necessary owing to the extreme slenderness of the structures, associated with the growing demand for expansion of the mobile cellular telephone system. An alternative means of meeting this demand is the sharing of existing structures to apply new loads. For other slender structures subjected to heavy loads, such as elevated water storage reservoirs, this verification process is mandatory.

The comparison of the FEM results with those of Rayleigh's method indicated that the frequency given by the former was initially 3.01\% lower than that yielded by the latter, whereas for buckling, the FEM results were $14.33 \%$ lower too. The difference was not as large for the frequency, and it is considered to be acceptable for engineering practice; however, for buckling, the difference was found to be significant. Considering the values at the final time, the difference was computed to be $5.94 \%$ for frequency and $21.45 \%$ for buckling. Although the frequency difference is larger in this case, it is still considered to be reasonable, as there is usually a safety margin of around 40\% (EN 1992-1-1, 2004), which includes model errors. Silva et al. (2013) studied 90 RC towers similar to the one investigated in this study and developed a procedure to compute the dynamic wind effects on such a structure. In one approach, they proposed that the dynamic magnification due to wind loading is linearly proportional to the first natural vibration frequency; thus, a decrement in the frequency is proportional to an increment in the dynamic load. For buckling, this difference is extremely large and may become infeasible for engineering purposes, as the FEM values are better. Similarly, considering the mathematical approach, the FEM involves many more vectors in the function vector space compared to Rayleigh's method, which requires only one function for the entire domain. These functions are the interpolation functions. Consequently, the FEM tends to be more precise, but this statement cannot be generalized. Simultaneously, a correction factor could be defined, as a function of the structure age, to fit both methods. These could be topics of future research, including tests and numerical analysis. A structural analysis further refined the grid of the FEM, considering 51 elements (seven elements more), and the results were similar to those presented here (with differences of $0.2 \%$ for the buckling load and $0.1 \%$ for the frequency), implying that the adopted discretization is adequate.

Wahrhaftig and Brasil (2017) performed an experimental investigation of the wind loads on slender towers by using low frequencies such as those employed in this study. As can be seen in Figure 10, they captured the effects of the frequencies in the acceleration measured on site. It was observed that the first frequency was the most important one in the behavior of the structure, being responsible for more than $90 \%$ of the acceleration of the structure. The second frequency had a small influence, and higher frequencies did not influence the dynamic loads at all. Considering the root sum square (RSS) to combine the responses of several modes, the first mode is responsible for more than $99 \%$ of the dynamic effects of the wind loading. Therefore, the computation of the first vibration frequency, in addition to the first mode, is crucial in this type of design. It is important to state that this kind of structures, used as telecommunication towers, has the function of transmitting electromagnetic waves from the tower to the cell phones and from one tower to other. In this case, the displacements and rotations of a given section may cause loss of signal and consequently loss of the communication between towers. So, during the design process it is necessary to introduce constraints limiting the rotation of the cross-sections to avoid loss of signal. 


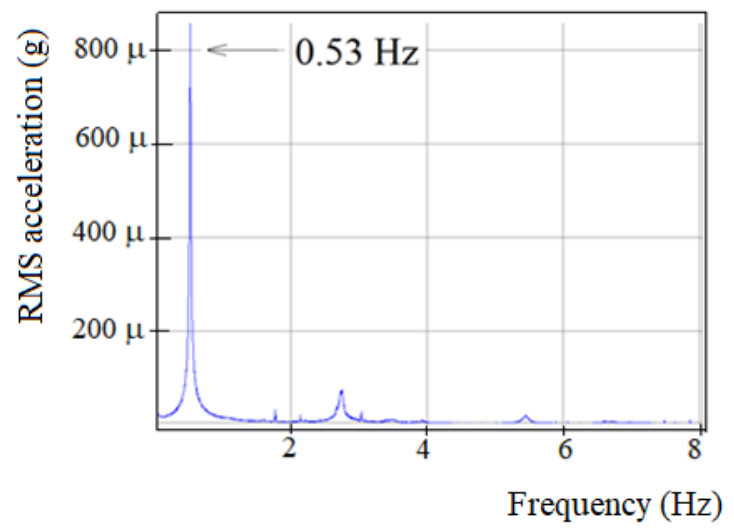

Figure 10. Experimentally obtained structural spectrum response (Wahrhaftig and Brasil, 2017).

\section{CONCLUSIONS}

In this study, a new way of application of an analytical procedure for computing the first natural vibration frequencies of RC slender towers was investigated. The method was applied to a 46-m-high RC telecommunication tower, and the results were compared with those obtained using the FEM. The buckling critical load was computed as well, by considering the geometrical and physical nonlinearities in addition to the soil-structure interaction. To account for these factors, the effects of cracking, as a cause of stiffness reduction, and material creep were included. The properties of the cross-sections changed as functions of the height of the structure above the ground. All of the analysis performed in this study was conducted using only one shape function, which included clear boundary conditions. The solution developed in this study is based on Rayleigh's method conducted by adopting a single shape function and considering the boundary conditions. The main contributing of this method is that the first natural vibration frequency can be calculated accurately for relatively complex problems without sophisticated tools that would require considerable modeling time and expensive software. An important application of the proposed mathematical procedure is the calculation of wind-induced forces. For the considered high-rise towers, the main loading comprises the wind-induced forces. This type of slender cantilever structure, when excited by wind, usually vibrates mainly in the first mode, and the equations developed in this study are thus useful for practical engineering applications. The proposed technique can also be applied to similar structures with slightly different geometries and mass distributions.

Excellent agreement was observed between the first vibration frequencies obtained using the proposed method and FEM analysis. Specifically, the difference between the results of the proposed method and FEM analysis was only $3.0 \%$ initially and $6.3 \%$ finally, considering creep. As this type of structure is designed with a safety margin of $40 \%$, which also includes the model errors, these differences are very reasonable for practical engineering purposes. It was noted in the present study that the effect of creep reduces the first frequency by $9.3 \%$, which indicates that it is important to consider this effect on the material.

However, the buckling load computed using this analytical method was $13.9 \%$ larger than that given by the FEM. A correction factor function could be used to fit the results and minimize the error between the different formulations. The difference between the results could be related to the fact that many more interpolation functions are used in FEM analysis than in Rayleigh's method, in which only one function is used for the entire domain of the problem. However, confirming this statement is not a straightforward task. Future analysis and specific studies will be required to obtain an appropriate conclusion. Therefore, further investigation, including the use of experimental methods, is necessary to complement this study.

Author's Contributions: Conceptualization, AM Wahrhaftig and RMLRF Brasil; Methodology, AM Wahrhaftig, MA da Silva and RMLRF Brasil; Investigation, AM Wahrhaftig, MA da Silva and RMLRF Brasil; Writing - original draft, AM Wahrhaftig; Writing - review \& editing, AM Wahrhaftig, MA da Silva; Supervision, RMLRF Brasil.

Editor: Pablo Andrés Muñoz Rojas. 


\section{References}

Amini F, Bitaraf M, Nasaba MSE, Javidan MM. (2018). Impacts of soil-structure interaction on the structural control of nonlinear systems using adaptive control approach. Eng Struct, https://doi.org/10.1016/j.engstruct.2017.11.071

Amiri AK, Bucher C. (2017). A procedure for in situ wind load reconstruction from structural response only based on field testing data. J Wind Eng Ind Aerodyn, https://doi.org/10.1016/j.jweia.2017.04.009

Arco DC, Aparicio ÁC, Maŕı AR. (2001). Preliminary design of prestressed concrete stress ribbon bridge. J Bridge Eng, https://doi.org/10.1061/(ASCE)1084-0702(2001)6:4(234)

Armand SC, Lin PP. (1993). Influence of mass moment of inertia on the modes of a preloaded solar array mast. Finite Elem Anal Des, https://doi.org/10.1016/0168-874X(93)90029-P

Assmann A, Reinhardt HW. (2014). Tensile creep and shrinkage of SAP modified concrete. Cem Concr Res, https://doi.org/10.1016/j.cemconres.2014.01.014

Awrejcewicz J, Krysko AV, Zagniboroda NA, Dobriyan VV, Krysko VA. (2014). On the general theory of chaotic dynamics of flexible curvilinear Euler-Bernoulli beams. Nonlinear Dyn, https://doi.org/10.1007/s11071-014-1641-5

Awruch AM, Gomes HM. (2015). Análise da confiabilidade de estruturas de concreto armado com uma metodologia para inclusão de efeitos estocásticos de propriedades dos materiais. Revista Internacional de Métodos Numéricos para Cálculo y Diseño en Ingeniería, https://doi.org/10.1016/j.rimni.2014.06.001

Bathe K-J, Wilson EL, (1973). Solution methods for eigenvalue problems in structural mechanics, Int J Numer Methods Eng, https://doi.org/10.1002/nme.1620060207

Boshoff WP, van Zijl GPAG. (2007). Time-dependent response of ECC: Characterisation of creep and rate dependence. Cem Concr Res, https://doi.org/10.1016/j.cemconres.2007.02.001

Brasil RMLRF, Silva MA, Wahrhaftig AM. (2007). Nonlinear dynamic analysis based on experimental data of RC telecommunication towers to wind loading. 12th Int Conf Wind Eng: ICWE 12, Cairns, Australia, July 1-6.

CEB-FIP Model Code (1990). Design code. Lausanne: Comité Euro-International du Béton.

Challamel N, Hellesland J. (2013). Buckling of softening columns in a continuum damage mechanics perspective - Local versus non-local formulation. Eur J Mech-A/Sol, https://doi.org/10.1016/j.euromechsol.2012.11.007

Challamel N, Lanos C, Casandjian, C. (2005). Creep damage modelling for quasi-brittle materials, Eur J Mech-A/Sol, https://doi.org/10.1016/j.euromechsol.2005.05.003

Challamel N, Picandet V, Collet B, Michelitsch T, Elishakoff I, Wang CM. (2015a). Revisiting finite difference and finite element methods applied to structural mechanics within enriched continua. Eur J Mech-A/Solids, https://doi.org/10.1016/j.euromechsol.2015.03.003

Challamel N, Picandet V, Elishako I, Wang CM, Collet B, Michelitsch T. (2015b). On nonlocal computation of eigenfrequencies of beams using finite difference and finite element methods. Int J Struct Stab Dyn, https://doi.org/10.1142/S0219455415400088

Charpin L, Sanahuja J. (2017). Creep and relaxation Poisson's ratio: Back to the foundations of linear viscoelasticity. Application to concrete. Int J Sol Struct, https://doi.org/10.1016/j.ijsolstr.2017.02.009.

Clough RW, Penzien J. (1993). Dynamics of structures. 2nd ed. Taiwan: McGraw Hill International Editions.

Delsaute B, Torrenti J-M, Staquet S. (2017). Modeling basic creep of concrete since setting time. Cem Con Comp, http://dx.doi.org/10.1016/j.cemconcomp.2017.07.023.

Deng J, Liu Y, Zhang Z, Liu W. (2017). Stability analysis of multi-span viscoelastic functionally graded material pipes conveying fluid using a hybrid method. Eur J Mech-A/Sol, https://doi.org/10.1016/j.euromechsol.2017.04.003

Ding H, Tan X, Dowell EH. (2017). Natural frequencies of a super-critical transporting Timoshenko beam. Eur J Mech-A/Sol, https://doi.org/10.1016/j.euromechsol.2017.06.007

Durbey C, Hansen SO. (1996). Wind loads on structures. England: John Wiley \& Sons.

El-Sawy KM, Sweedan AM, Martini MI. (2009). Major-axis elastic buckling of axially loaded castellated steel columns. ThinWalled Struct, 47(11):1295-304. https://doi.org/10.1016/j.tws.2009.03.012 
Eurocode Standard (2010), EN 1991-1-4 - Eurocode 1: Actions on structures - Part 1-4: General actions - Wind actions. The European Union Per Regulation (European Committee for Standardization - CEN)

European Standard (2004). EN 1992-1-1 - Eurocode 2: Design of concrete structures - Part 1: General rules and rules for buildings.

Granger L. (1995). Deferred behavior of concrete in nuclear power plant enclosures: analysis and modeling. Mechanics National School of Roads and Bridges, French (Comportement différé du béton dans les enceintes de centrales nucléaires: analyse et modélisation. Mécanique [physics.med-ph]. Ecole Nationale des Ponts et Chaussées, Français) Ph.D. thesis.

Hamed E, Bradford MA. (2010). Creep in concrete beams strengthened with composite materials. Eur J Mech-A/Sol, https://doi.org/10.1016/j.euromechsol.2010.05.007

Han B, Jiao YY, Xie HB, Zhu L. (2017a). Creep of compression fly ash concrete-filled steel tubular members. Thin-Walled Struct, https://doi.org/10.1016/j.tws.2017.01.034

Han B, Xie HB, Zhu L, Jiang P. (2017b). Nonlinear model for early age creep of concrete under compression strains. Constr Build Mater, https://doi.org/10.1016/j.conbuildmat.2017.04.119

Hołowaty J. (2015). Creep and shrinkage of concrete in Eurocode 2 and Polish bridge standards - necessity for implementation. J Civil Eng Archi, https://doi.org/10.17265/1934-7359/2015.04.009.

Houmat A. (2015). Nonlinear free vibration analysis of variable stiffness symmetric skew laminates. Eur J Mech-A/Sol, https://doi.org/10.1016/j.euromechsol.2014.10.008

Irfan-ul-Hassan M, Pichler B, Reihsner R, Hellmich, C. (2016). Elastic and creep properties of young cement paste, as determined from hourly repeated minute-long quasi-static tests. Cem Concr Res, https://doi.org/10.1016/j.cemconres.2015.11.007

Jia X. (2013). Revisiting the failure mode of a RC hyperbolic cooling tower, considering changes of material and geometric properties. Eng Struct, https://doi.org/10.1016/j.engstruct.2012.02.018

Jiao D, Shi C, Yuan Q, An X, Liu Y, Li H. (2017). Effect of constituents on rheological properties of fresh concrete - a review. Cem Concr Compos, https://doi.org/10.1016/j.cemconcomp.2017.07.016

Kwak H-G, Kim J-K. (2004). Ultimate resisting capacity of slender RC columns. Comp Struct, https://doi.org/10.1016/j.compstruc.2004.02.019

Leissa AW. (2005). The historical bases of the Rayleigh and Ritz methods. J Sound Vib, https://doi.org/10.1016/j.jsv.2004.12.021

Liu J, Zhu WD, Charalambides PG, Shao YM, Xu YF, Fang XM. (2016). A dynamic model of a cantilever beam with a closed, embedded horizontal crack including local flexibilities at crack tips. J Sound Vib, https://doi.org/10.1016/j.jsv.2016.04.036

Lo YL, Kim YC, Yoshida A. (2017). Effects of aerodynamic modification mechanisms on interference from neighboring buildings. J Wind Eng Ind Aerodyn, https://doi.org/10.1016/j.jweia.2017.06.018

Lord Rayleigh. (1877). Theory of sound. New York: Dover Publications, re-issued.

Lubbers LA, van Hecke M, Coulais C. (2017). A nonlinear beam model to describe the postbuckling of wide neo-Hookean beams. J Mech Phys Sol, https://doi.org/10.1016/j.jmps.2017.06.001

Masjedi PK, Maheri A. (2017). Chebyshev collocation method for the free vibration analysis of geometrically exact beams with fully intrinsic formulation. Eur J Mech-A/Sol, https://doi.org/10.1016/j.euromechsol.2017.07.014

Mehta PK, Monteiro PJM, Filho AC. (1994). Concreto: estrutura, propriedades e materiais (Concrete: structure, properties and materials). São Paulo, Brazil: PINI.

Milašinovic' DD, Landovic A. (2018). Rheological-dynamical analogy for analysis of vibrations and low cycle fatigue in internally damped inelastic frame structures, Comp Struct, https://doi.org/10.1016/j.compstruc.2017.11.001

NBR 6118:2014 (2014). NBR 6118:2014 - Design of structural concrete - procedure. Rio de Janeiro, Brazil: Brazilian Association for Standardization (ABNT).

Neville AM. (1997). Propriedades do concreto (Concrete proprieties). São Paulo, Brazil: PINI. 
Noh HC. (2006). Nonlinear behavior and ultimate load bearing capacity of reinforced concrete natural draught cooling tower shell. Eng Struct, https://doi.org/10.1016/j.engstruct.2005.08.016

Pascon JP. (2018). Large deformation analysis of functionally graded visco-hyperelastic materials. Comp Struct, https://doi.org/10.1016/j.compstruc.2018.06.001

Pozos-Estrada, A, Hong, H P. (2015). Sensitivity analysis of the effectiveness of tuned mass dampers to reduce the windinduced torsional responses. Lat Am J Solids Stru, http://dx.doi.org/10.1590/1679-78251856

Pradhan KK, Chakraverty S. (2017). Natural frequencies of shear deformed functionally graded beams using inverse trigonometric functions. J Brazilian Soc Mech Sci Eng, https://doi.org/10.1007/s40430-016-0701-9

Pramod ALN, Natarajan S, Ferreira AJM, Carrera E, Cinefra M. (2017). Static and free vibration analysis of cross-ply laminated plates using the Reissner-mixed variational theorem and the cell based smoothed finite element method. Eur J Mech-A/Sol, https://doi.org/10.1016/j.euromechsol.2016.10.006

Qian Y, Kawashima S. (2016). Use of creep recovery protocol to measure static yield stress and structural rebuilding of fresh cement pastes. Cem Concr Res, https://doi.org/10.1016/j.cemconres.2016.09.005

Ranaivomanana N, Multon S, Turatsinze A. (2013). Tensile, compressive and flexural basic creep of concrete at different stress levels. Cem Concr Res, https://doi.org/10.1016/j.cemconres.2013.05.001

Rossi P, Tailhan JL, Le Maou F. (2013). Comparison of concrete creep in tension and in compression: Influence of concrete age at loading and drying conditions. Cem Concr Res, https://doi.org/10.1016/j.cemconres.2013.04.001

SAP2000 (2015). Analysis reference manual. Integrated software for structural analysis and design. Berkeley, California: Computers and Structures, Inc.

Scheble M, Rauschert AG, Converti J. (2003). An improved Rayleigh-Ritz substructure synthesis method adopting mixed coordinates. Int J Struct Stab Dyn, https://doi.org/10.1142/S021945540300104X

Sellier A, Multon S, Buffo-Lacarrière L, Vidal T, Bourbon X, Camps G. (2016). Concrete creep modelling for structural applications: non-linearity, multi-axiality, hydration, temperature and drying effects. Cem Concr Res, https://doi.org/10.1016/j.cemconres.2015.10.001

Shang HY, Machado RD, Filho JEA, Arndt M. (2017). Numerical analysis of plane stress free vibration in severely distorted mesh by generalized finite element method. Eur J Mech-A/Sol, https://doi.org/10.1016/j.euromechsol.2016.11.006

Silva MA, Arora, J, Brasil, RMLRF. (2013). Dynamic analysis of pre-cast RC telecommunication towers using a simplified model. Design and Analysis of Materials and Engineering Structures, https://doi.org/10.1007/978-3-642-32295-2_8

Silva MA, Brasil RMLRF. (2006). Nonlinear dynamic analysis based on experimental data of RC telecommunication towers subject to wind loading. Math Prob Eng, http://dx.doi.org/10.1155/MPE/2006/46815

Simão PD. (2017). Influence of shear deformations on the buckling of columns using the generalized beam theory and energy principles. Eur J Mech-A/Sol, https://doi.org/10.1016/j.euromechsol.2016.09.015

Simiu E, Scanlan R. (1996). Wind effects on structures. New York: John Wiley \& Sons.

Su L, Wang YF, Mei SQ, Li PF. (2017). Experimental investigation on the fundamental behavior of concrete creep. Constr Build Mater, https://doi.org/10.1016/j.conbuildmat.2017.06.162

Temple G, Bickley WG. (1933). Rayleigh's principle and its applications to engineering. Humphrey Milford, London: Oxford University Press.

Timoshenko SP, Gere JM. (1961). Theory of elastic stability. 2nd ed. New York: McGraw-Hill Book Company.

Uzny S. (2011). An elastically supported geometrically nonlinear slender system subjected to a specific load in respect of bifurcational load and free vibrations. Int J Bifurc Chaos, DOI:10.1142/S0218127411030295

Vieira, G S, Brito, J L V, Loredo-Souza, A M. (2018). Experimental study of the neighborhood effects on the mean wind loading over two equivalent high-rise buildings. Lat Am J Solids Stru, http://dx.doi.org/10.1590/1679-78253560

Wahrhaftig AM, Brasil RMLRF, Balthazar JM. (2013). The first frequency of cantilever bars with geometric effect: a mathematical and experimental evaluation. J Brazilian Soc Mech Sci Eng, https://doi.org/10.1007/s40430-013-0043-9 
Wahrhaftig AM, Brasil RMLRF. (2016). Representative experimental and computational analysis of the initial resonant frequency of largely deformed cantilevered beams. Int J Sol Struct, https://doi.org/10.1016/j.ijsolstr.2016.10.018

Wahrhaftig AM, Brasil RMLRF. (2017). Vibration analysis of mobile phone mast system by Rayleigh method. Appl Math Modell, https://doi.org/10.1016/j.apm.2016.10.020

Wahrhaftig AM. (2013). A técnica de discretização em barras comprimidas e as frequências naturais de vibração. Bilbao, España: Congreso de Métodos Numéricos en Ingeniería (CMN).

Wahrhaftig AM. (2017). Analysis of the first modal shape using two case studies. Int J Comput Meth, https://doi.org/10.1142/S0219876218400194

Wang XP. (2014). Influences of concrete creep and temperature deformation on vehicle travelling across bridge. Appl Mech Mater, https://doi.org/10.4028/www.scientific.net/AMM.556-562.655

Wilson EL, Bathe KJ. (1976). Numerical methods in finite element analysis. Englewood Cliffs, New Jersey: Prentice-Hall, Inc.

Wilson EL, Habibullah A. (1987). Static and dynamics analysis of multi-story buildings, including P-Delta effects. Earthq Spect, https://doi.org/10.1193/1.1585429

Yang H, Chen Z, Zhang H, Fan, J. (2016). Dynamic analysis of train-rail-bridge interaction considering concrete creep of a multispan simply supported bridge. Adv Struct Eng, https://doi.org/10.1260/1369-4332.17.5.709.

Zuo H, Bi K, Hao H. (2018). Dynamic analyses of operating offshore wind turbines including soil structure interaction. Eng Struct, https://doi.org/10.1016/j.engstruct.2017.12.001 